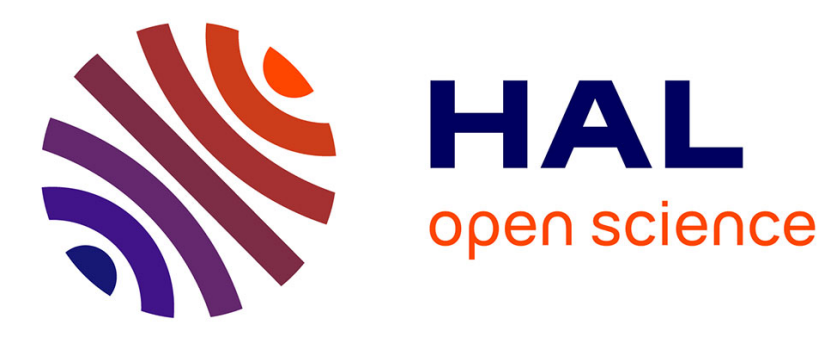

\title{
VHH characterization.Recombinant VHHs: Production, characterization and affinity
}

Eric Chabrol, Johann Stojko, Alexandre Nicolas, Thomas Botzanowski, Benjamin Fould, Mathias Antoine, Sarah Cianférani, Gilles Ferry, Jean A. Boutin

\section{To cite this version:}

Eric Chabrol, Johann Stojko, Alexandre Nicolas, Thomas Botzanowski, Benjamin Fould, et al.. VHH characterization.Recombinant VHHs: Production, characterization and affinity. Analytical Biochemistry, 2020, 589, pp.113491. 10.1016/j.ab.2019.113491 . hal-02566741

\section{HAL Id: hal-02566741 \\ https://hal.science/hal-02566741}

Submitted on 15 Dec 2020

HAL is a multi-disciplinary open access archive for the deposit and dissemination of scientific research documents, whether they are published or not. The documents may come from teaching and research institutions in France or abroad, or from public or private research centers.
L'archive ouverte pluridisciplinaire HAL, est destinée au dépôt et à la diffusion de documents scientifiques de niveau recherche, publiés ou non, émanant des établissements d'enseignement et de recherche français ou étrangers, des laboratoires publics ou privés. 


\section{VHH characterization.}

5 Eric Chabrol ${ }^{1 \&}$, Johann Stojko ${ }^{1 \&}$, Alexandre Nicolas ${ }^{1}$, Thomas Botzanowski², Benjamin Fould ${ }^{1}$, Mathias 6 Antoine $^{1}$, Sarah Cianférani ${ }^{2}$, Gilles Ferry ${ }^{1}$, Jean A. Boutin ${ }^{1,3, *}$

7

81 PEX Biotechnologies, Chimie, Biologie, Institut de Recherches Servier, 125 chemin de Ronde, 978290 Croissy-sur-Seine, France

102 Laboratoire de Spectrométrie de Masse BioOrganique, Université de Strasbourg, CNRS, IPHC, 11 UMR 7178, 67000 Strasbourg, France

123 Institut de Recherches Internationales Servier, 50 rue Carnot, 92284 Suresnes Cedex, France

14 \& These two authors contributed equally to the work

$15 *$ To whom correspondence should be addressed: Dr. JA Boutin, Institut de Recherches Internationales 16 Servier, 50 rue Carnot, 92284 Suresnes Cedex, France. Email : jean.boutin@servier.com; phone : $17+33155724400$

19 Running title: VHH expression and characterization

20 Total number of manuscript pages: 41

21 Tables: 8

22 Figures: 10 
- VHH are small antibody-like proteins. They are entering the therapeutic arsenal.

- VHH purity, homogeneity, structure and affinity towards their targets are described.

- An analytical workflow to qualify those proteins is presented to validate the molecules. 
32 Abstract: Among the biological approaches to therapeutics, are the cells, such as CAR-T cells engineered 33 or not, the antibodies armed or not, and the smaller protein scaffolds that can be modified to render them 34 specific of other proteins, à la façon of antibodies. For several years, we explored ways to substitute 35 antibodies by nanobodies (also known as VHHs), the smallest recognizing part of camelids' heavy-chain 36 antibodies: production of those small proteins in host microorganisms, minute analyses, characterization, 37 and qualification of their affinity towards designed targets. Here, we present three standard VHHs 38 described in the literature: anti-albumin, anti-EGF receptor and anti-HER2, a typical cancer cell surface 39 associated protein. Because they differ slightly in global structure, they are good models to assess our 40 body of analytical methodologies. The VHHs were expressed in several bacteria strains in order to 41 identify and overcome the bottlenecks to obtain homogeneous preparations of this protein. A large panel 42 of biophysical tools, ranging from spectroscopy to mass spectrometry, was here combined to assess VHH 43 structural features and the impact of the disulfide bond. The routes are now ready to move to more 44 complex VHHs raised against specific targets in numerous areas including oncology.

46 Keywords: VHH, expression, characterization, structure, affinity, CD, differential scanning fluorimetry, 47 mass spectrometry, ion-mobility, hydrogen/deuterium exchange, surface plasmon resonnance. 


\section{INTRODUCTION:}

51 Antibody therapy has taken a new boost these last years, due to the generalization of recombinant protein 52 production techniques, on one hand and to the use of armed antibodies $(\mathrm{Ab})$ on the other [1,2]. Indeed, 53 several huge successes were recorded in many therapeutic areas, including, but not limited to cancer [3], 54 diabetes [4], poisoning [5], immune-inflammation [6], and infectious diseases [7].

Anti-cancer therapy has been one of the main sources of progress [8] in this area, especially by pioneering and using in clinic armed antibodies also known as antibody-drug conjugates (ADCs) [9]. Basically, this consists to load a cytotoxic compound on an antibody and use it as a cargo to selectively deliver the conjugated drug on its target: a cell expressing the protein against which it has been raised [10]. The goal is to deliver the payload to the cancer cells with a higher efficiency thanks to the selectivity of the antibody, in order to potentializing its efficacy while diminishing its off-target effects (see Thomas et al for review [11]). Although this has been a breakthrough in the anticancer armada, with numerous successful examples [12-15], this approach essentially suffers from practical obstacles: the recombinant synthesis of those antibodies is not only tricky but also quite expensive, even if the amount of this product injected to patients remains, in some cases but not all, remarkably small due to the high affinity of the antibody for its target [16]. Furthermore, once purified to apparent homogeneity, antibodies usually include an intrinsic micro-heterogeneity, essentially due to many possible minute modifications including glycosylations [17,18] - of some amino acids in the Ab heavy chain (see for example Husson et al [19]). This heterogeneity can be further increased by chemical modifications induced upon conjugation of the antibody with a cytotoxic compound, leading to new chemical species containing the monoclonal antibody $(150 \mathrm{kDa})$ as well as a defined number of molecules of the cytotoxic compound [16]. Despite those difficulties and the obvious benefit brought to the patients, many progresses should and will be done in the future.

Alternative approaches are scrutinized, and particularly those concerning smaller protein molecules such as ankyrin (see review by Skerra [20]). The original idea was to take advantage of the particular single heavy chain antibody from camelids and sharks [21]. Indeed, the smallest intact antigen-binding part of those huge proteins is the variable domain of the heavy chain [22,23]. Those protein parts were called nanobodies or VHHs. Their sequences retain the antibody specificity for the targets they were raised against. Therefore, a smaller and less complex protein recognizing a given target could be used as a substitute to monoclonal antibodies. VHHs have been reported against many proteins that are supposedly preferentially expressed in cancer cells, such as PD-1 [24], EGFR [25], HER2 [26], HLA-DR [27], 
81 GFRA1 [28], HSA [29] and many others. Needless to stress that the beauty of the approach relies on the 82 specific nature of the protein expressed at the surface of the targeted cells (cancerous or others) and 83 recognized by the VHHs. An anti-HER2 VHHs have been shown to be valuable tools for breast cancer 84 cells detection [30-32]. Aside from oncology, those tools could also be used in many different application 85 areas, including diagnosis [33].

86 To date, however, there is a clear deficit in peptide (and protein) characterization, particularly regarding 87 their homogeneity [34]. Despite clear warnings in excellent reviews on the subject [35,36], as well as 88 rapid progress in analytical methodologies, it still felt that many more characterization approaches should 89 be systematically developed, in particular concerning therapeutic biologics [37] (as opposed to research 90 biologics). Indeed, whenever a polypeptide is produced, whether from recombinant or synthetic 91 approaches, it is too often assumed, on the unique basis of a SDS-PAGE electrophoresis and a liquid 92 chromatography coupled to mass spectrometry analysis (LC-MS) that the peptide is pure and 93 homogeneous, while the expected biological activity is at the rendezvous. A recent discussion on this 94 subject has been put forward for synthetic peptide [34], while examples have been reported for 95 recombinant proteins [19]. In fact, it is far from clear that such a limited characterization guarantees the 96 homogeneity of the preparation, leading to a false interpretation about the amount of such polypeptide 97 active in a given preparation. Led by this idea, we wanted to thoroughly describe the characteristics of 98 VHHs, as they turned out to be promising alternatives to bigger biologics on the threshold of therapeutic 99 use. While VHHs have been so far produced against many different targets, and very well characterized in 100 terms of antigen recognition, their structure and overall biophysical characteristics yet remain scarcely 101 documented.

102 In the present paper, we aimed at benchmarking the production and characterization workflows of VHH, 103 using an anti-HER2 VHH as a model. This exploratory study, combining solution-based as well as gas104 phase cutting edge approaches, enabled to broaden our functional and structural knowledge of this 105 emerging class of proteins and laid the ground for future investigations. As we entered this new era during 106 which small biologics, and particularly VHHs will take over as first intention drugs against cancers (see 107 discussions on the various advantages of these solutions [38,39]), it will be crucial that the biochemical 108 and analytical methods for a complete characterization of those entities become available with published 109 backgrounds to help promoting and developing the rise of such molecules in the therapeutic arsenal. 


\section{Materials and methods}

1132.1 Cloning, expression and purification. Coding DNA fragments of the various VHHs have been E.coli 114 codon optimized, synthetized and cloned into high copy expression vectors with a poly-His-tag at the C115 terminal end of each protein. We used two different vectors, pET-15b and pET-20b, respectively for a 116 cytoplasmic and periplasmic expression of the anti-HER2 VHH and only pET-15b for a cytoplasmic 117 expression of both anti-HSA and anti-EGFR1 VHHs. The genetic constructs were transformed into two 118 different E.coli strains for the anti-HER2 VHH: Shuffle T7 express and BL21(DE3) for the cytoplasmic and periplasmic expression respectively and only Shuffle T7 express strain for both anti-HSA and antiEGFR1 VHHs. Bacteria were cultured in a LB medium with ampicillin $(100 \mu \mathrm{g} / \mathrm{mL}$ final concentration) and the expression was induced with $0.1 \mathrm{mM}$ IPTG when the OD at $600 \mathrm{~nm}$ reached 0.6. The temperature was decreased from $37^{\circ} \mathrm{C}$ to $22^{\circ} \mathrm{C}$ during expression that was carried on overnight. Cells were harvested by centrifugation $\left(5000 \mathrm{~g}, 20 \mathrm{~min}, 4^{\circ} \mathrm{C}\right)$ and lysed by lysozyme membrane digestion $(1 \mathrm{mg} / \mathrm{mL})$ into a $20 \mathrm{mM}$ Tris- $\mathrm{HCl} \mathrm{pH} 8,300 \mathrm{mM} \mathrm{NaCl}$ buffer supplemented with $10 \mu \mathrm{g} / \mathrm{mL}$ DNAse1 and protease inhibitor cocktail during $30 \mathrm{~min}$ at room temperature. Cell fragments were harvested by ultracentrifugation $\left(100000 \mathrm{x} \mathrm{g}, 30 \mathrm{~min}, 4^{\circ} \mathrm{C}\right)$. The supernatant containing the his-tagged VHHs was then subjected to a three-steps purification. The supernatant was first injected onto an equilibrated Ni-NTA agarose resin (Qiagen) with a $20 \mathrm{mM}$ Tris- $\mathrm{HCl} \mathrm{pH} \mathrm{8,} 300 \mathrm{mM} \mathrm{NaCl}, 10 \mathrm{mM}$ imidazole buffer. The column was washed with $20 \mathrm{mM}$ imidazole and the proteins were eluted with $250 \mathrm{mM}$ imidazole. The second purification step was performed by cation exchange chromatography (IEX, SourceS, GE healthcare) after dialysis of the sample against a buffer composed of $50 \mathrm{mM}$ Tris- $\mathrm{HCl} \mathrm{pH} 7.5,50 \mathrm{mM}$ $\mathrm{NaCl}$. The sample was injected onto the cation exchange column previously equilibrated with the dialysis buffer. Elution was then achieved with a linear gradient of $1 \mathrm{M} \mathrm{NaCl}$ in $50 \mathrm{mM}$ Tris- $\mathrm{HCl} \mathrm{pH}$ 7.5. The eluted proteins were then concentrated on a $3 \mathrm{kDa}$ MWCO Amicon device (Millipore). The concentrated sample was finally purified by sized exclusion chromatography (SEC) using a HiLoad 26/600 Superdex transformed with the pET15b vector containing the anti-HER2 VHH DNA was used to express the VHH in IB. Bacteria were cultured in a MagicMedia ${ }^{\mathrm{TM}}$ E. coli Expression Medium (ThermoFisher Scientific, Villebon, France) with ampicillin (final concentration at $100 \mu \mathrm{g} / \mathrm{mL}$ ). The culture was performed overnight at $37^{\circ} \mathrm{C}$ following the supplier recommendation. Bacteria were then harvested by centrifugation

$142\left(5000 \mathrm{x} \mathrm{g}, 20 \mathrm{~min}, 4^{\circ} \mathrm{C}\right)$ and lysed as previously described. After an ultracentrifugation step (100 $000 \mathrm{x} \mathrm{g}$, $14320 \mathrm{~min}, 4^{\circ} \mathrm{C}$ ), the supernatant was removed and stored for further use. The pellet was washed once with $14430 \mathrm{~mL} / \mathrm{L}$ of culture in a buffer composed of $20 \mathrm{mM}$ Tris- $\mathrm{HCl} \mathrm{pH} 8,150 \mathrm{mM} \mathrm{NaCl}, 1 \mathrm{M}$ Urea and $1 \%$ 
Triton X-100 and resuspended using a $45 \mathrm{~mL}$ Potter-Elvehjem homogeneizer (Sigma). This preparation was then pelleted by ultracentrifugation $(100000 \mathrm{x} \mathrm{g}, 30 \mathrm{~min})$ at $4^{\circ} \mathrm{C}$. Again, the supernatant was removed and stored. The resulting pellet was washed a second time using the same method but with a $20 \mathrm{mM}$ Tris$\mathrm{HCl} \mathrm{pH} 8,150 \mathrm{mM} \mathrm{NaCl}$ buffer. The wash solution was removed and stored, while the pellet was finally solubilized in $30 \mathrm{~mL}$ of $20 \mathrm{mM}$ Tris- $\mathrm{HCl} \mathrm{pH} \mathrm{8,} 6 \mathrm{M}$ guanidium (Gdn) buffer using a Potter-Elvehjem homogeneizer. After an ultimate ultracentrifugation $\left(100000 \mathrm{x} \mathrm{g}, 30 \mathrm{~min}, 4^{\circ} \mathrm{C}\right)$, all supernatant and wash fractions collected during the process and containing the denatured VHHs were mixed together in order to proceed to the refolding step. Therefore, the resulting sample was supplemented with $3 \mathrm{mM}$ of reduced glutathione and $0.3 \mathrm{mM}$ of oxidized glutathione then incubated at $4^{\circ} \mathrm{C}$ at a final concentration of $1 \mathrm{mg}$ protein $/ \mathrm{mL}$ for $48 \mathrm{~h}$. The refolded proteins were then dialysed overnight at $4{ }^{\circ} \mathrm{C}$ against 100 volumes of a buffer containing $50 \mathrm{mM}$ TAPS $\mathrm{pH} 8,50 \mathrm{mM} \mathrm{NaCl}, 0.6 \mathrm{M}$ Gdn and $0.8 \mathrm{M}$ L-Arginine. The dialysis process was repeated using a $20 \mathrm{mM}$ Tris- $\mathrm{HCl} \mathrm{pH} 8$ and $150 \mathrm{mM} \mathrm{NaCl}$ buffer until a one million final dialysis factor was reached. Purification was first performed by affinity chromatography as previously described and then by hydrophobic chromatography (HIC) to separate the oxidized from the reduced forms of the anti-HER2 VHH using a $5 \mathrm{~mL}$ butyl High Performance column (GE Healthcare) for $10 \mathrm{mg}$ of injected proteins. Briefly, the refolded and dialyzed sample were diluted in a buffer comprising $100 \mathrm{mM}$ phosphate $\mathrm{pH} 7.4$ and 1.5 M ammonium sulphate, and injected on the column connected to an Akta FPLC instrument. The proteins were eluted using a gradient of the equilibrium buffer $\left(100 \mathrm{mM} \mathrm{NaH} \mathrm{PO}_{4}\right.$ $\mathrm{pH}$ 7.4). The fractions of interest were finally concentrated and dialysed in a $20 \mathrm{mM}$ Tris- $\mathrm{HCl} \mathrm{pH} 8$, $150 \mathrm{mM} \mathrm{NaCl}$ buffer, before being used for further characterizations.

2.3 Electrophoresis. SDS-Page experiments were performed using a 4-12\% Nu-Page ${ }^{\circledR}$ gel in MES buffer (Invitrogen, ThermoFisher) with a migration time of 90 minutes and a constant voltage of $120 \mathrm{~V}$. The non-reduced samples (NR) were diluted in a LDS® buffer (Invitrogen) supplemented with $30 \mathrm{mM}$ iodoacetamine and heated $2 \mathrm{~min}$ at $55^{\circ} \mathrm{C}$. The reduced samples (R) diluted in a $\operatorname{LDS}{ }^{\circledR}$ buffer supplemented with $50 \mathrm{mM}$ DTT (Thermo Scientific Pierce) were boiled $5 \mathrm{~min}$ at $95^{\circ} \mathrm{C}$. For each sample, about $2 \mu \mathrm{g}$ of proteins were loaded onto the gels. The molecular weight reference was a SeeBlue Plus 2 Prestained Standard ${ }^{\circledR}$ (Invitrogen) and the Coomassie blue was a Quick Coomassie Stain ${ }^{\circledR}$ from Generon (Slough, UK). Images were captured with a Gel Doc ${ }^{\mathrm{TM}}$ EZ Gel.

2.4 Analytical light scattering. Analytical light scattering (ALS) analyses were performed using a 1260 Infinity HPLC (Agilent) coupled to a light scattering detector Dawn8+ HELEOS II ${ }^{\circledR}$ and a refractive index detector Optilab T-rex ${ }^{\mathrm{TM}}$ (Wyatt Technology, Santa Barbara, CA). The size exclusion column was a BioSec3, $3 \mu \mathrm{m}, 100 \AA$, 4.6 x $300 \mathrm{~mm}$ (Agilent). The buffer used for the column equilibration and the

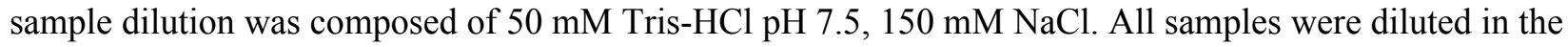


running buffer to contain $20 \mu \mathrm{g}$ of proteins for an injection of $30 \mu \mathrm{L}$ with a flow rate of $0.2 \mathrm{~mL} / \mathrm{min}$. The data were collected and analyzed using the Astra ${ }^{\circledR} 6.1$ software. spectrometer coupled to a JASCO MCB-100 mini-circulation bath and a JASCO MPTC-490S/15 6position Peltier Type Turret Cell Changer. The cuvettes used were Starna Scientific type 21/Q/1 quartz spectrophotometer cells with a path length of $1 \mathrm{~mm}$. CD, high tension voltage (HT) and absorbance signals were collected from 190 to $260 \mathrm{~nm}$ with standard sensitivity and data pitch of $0.1 \mathrm{~nm}$, a DIT of 1 sec, a bandwidth of $1 \mathrm{~nm}$, a scanning speed of $50 \mathrm{~nm} / \mathrm{min}$, a temperature gradient of $0.5^{\circ} \mathrm{C} / \mathrm{min}$, a temperature interval of $5^{\circ} \mathrm{C}$. Data were accumulated 5 times for each sample which was dialyzed against a $100 \mathrm{mM} \mathrm{NaH} \mathrm{PO}_{4} \mathrm{pH} 7.5$ buffer with a final concentration of $0.5 \mathrm{mg} / \mathrm{mL}$. The formula used to calculate the ellipticity was the following: $(33 \times \mathrm{A}$ ( 100$) /(1 \mathrm{x}$ Protein concentration / MW x (number of residues -1)) where A, 1 and MW correspond to the absorbance, the measure cell length and the molecular weight of the protein, respectively. The $\mathrm{CD}$ data were recorded at $25^{\circ} \mathrm{C}$ for each $\mathrm{VHH}$ and analysed using BeStSel, an online software enabling to calculate the proportion of secondary structures ${ }^{44,43}$. scattering experiments were performed on an OPTIM 2 ${ }^{\circledR}$ instrument (AVACTA Analytical, Wetherby , UK). Briefly, intrinsic fluorescence and CD signals from each VHH sample were measured through a temperature ramp ranging from $25^{\circ} \mathrm{C}$ to $90^{\circ} \mathrm{C}$ with an interval of $0.5^{\circ} \mathrm{C} / \mathrm{min}$ and a starting incubation time of $120 \mathrm{~s}$ and the data collected was treated with the AVACTA Analysis software. Each experiment was performed in triplicate at a concentration of $2 \mathrm{mg} / \mathrm{mL}$ in a $50 \mathrm{mM}$ Tris- $\mathrm{HCl} \mathrm{pH} 7.5,150 \mathrm{mM} \mathrm{NaCl}$ buffer.

2.7 Surface plasmon resonance. All experiments were performed on a Biacore T200 (GE Healthcare, Uppsala, Sweden) using a functionalized CM5 chip and the corresponding reagents from Biacore. Four flow-cells were activated by $50 \mu \mathrm{L}$ of an EDC/NHS mixture. Flow-cell one was blocked with $50 \mu \mathrm{L}$ of ethanolamine and used as a control surface. Flow-cell two three and four were functionalised up to a level of about 1000 resonance units (RU) with a $20 \mu \mathrm{g} / \mathrm{mL}$ solution of a recombinant human ErbB2 antigen (Sino Biological, Wayne, PA, USA, ref: 10004-H08H), a recombinant human EGFR1 antigen (Sino biological, ref: 10001-H08H) or a human serum albumin antigen (Sigma) in sodium acetate pH 5.0 buffer respectively. The immobilization procedure was performed in a PBS buffer (Biacore) supplemented with $0.005 \%$ of P20 surfactant. Increasing amounts of each $\mathrm{VHH}$ were injected at a $50 \mu \mathrm{L} / \mathrm{min}$ flow rate in

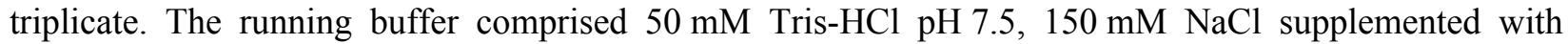
0.005\% P20 surfactant. Each protein was diluted twice into the running buffer with concentrations ranging 

from 0.122 to $125 \mathrm{nM}$ for anti-HER2 VHH, and from 0.195 to $100 \mathrm{nM}$ for anti-EGFR1 VHH and antiHSA VHH, respectively. The chips were regenerated with two cycles of 10 -sec injections of $3 \mathrm{M} \mathrm{MgCl}_{2}$ separated by a 900 -sec delay. The association phase and dissociation phase were run during 4 or 6 min and 15 min respectively. Sensorgrams were fitted with Langmuir equation using the BIAeval software. samples were performed on an Acquity UPLC H-Class Bio system (Waters, Manchester, UK) coupled to a Q-TOF mass spectrometer (Xevo G2-XS, Waters, Manchester, UK). A volume corresponding to 140 pmol of each sample was injected onto a reverse phase liquid chromatography column (BEH C4, 150 x $2.1 \mathrm{~mm}$, $300 \AA, 1.7 \mu \mathrm{m}$, Waters). Sample elution was carried-out at $40^{\circ} \mathrm{C}$ from mobile phases A (water, $0.1 \% \mathrm{FA}$ ) and $\mathrm{B}$ (acetonitrile, $0.1 \% \mathrm{FA}$ ) using a flow rate of $0.2 \mathrm{~mL} / \mathrm{min}$ and a 38 -min gradient applied as follows: $0 \% \mathrm{~B}$ during $1 \mathrm{~min}, 0$ to $10 \% \mathrm{~B}$ in $0.1 \mathrm{~min}, 10 \%$ to $40 \% \mathrm{~B}$ in $29.9 \mathrm{~min}, 40 \%$ to $90 \%$ in $2 \mathrm{~min}, 90 \%$ to $0 \%$ B in $0.1 \mathrm{~min}, 0 \%$ B during $4.9 \mathrm{~min}$. Signal acquisition was realized by both UV absorbance measurement at $280 \mathrm{~nm}$ and mass spectrometry. The instrument was set in the positive ion mode with a capillary voltage, a desolvation gas flow, a sampling cone voltage and a source temperature of $1.5 \mathrm{kV}, 800 \mathrm{~L} / \mathrm{h}, 80$ $\mathrm{V}$ and $120^{\circ} \mathrm{C}$ respectively. MS spectra were recorded in the mass range of 500-4000 m/z with a scan time of $1 \mathrm{~s}$. Calibration was performed using the singly charged ions produced by sodium iodide clusters diluted to $2 \mathrm{~g} / \mathrm{L}$ in a 1:1 (v/v) water:isopropanol solution, and an online mass correction with Leuenkephalin peptide as the lock mass. Data processing was carried out on Mass Lynx V4.1 (Waters, Manchester, UK). Relative quantification of chromatographically resolved species was performed by integrating their corresponding UV peak area.

2.9 Denaturing and native mass spectrometry. Anti-HER2 VHH samples were first buffer exchanged against a $100 \mathrm{mM}$ ammonium acetate (NH4Ac) solution at $\mathrm{pH} 7.5$ using gel filtration (Zeba $0.5 \mathrm{ml}$, Thermo Scientific, Rockford, IL, USA). Protein concentration was determined spectrophotometrically. NanoESI-MS characterization of these samples was next generated on a hybrid Q-TOF mass spectrometer with an ion mobility cell (Synapt G2-S HDMS, Waters, Manchester, UK) equipped with an automated chip-based nanoESI source (Triversa Nanomate, Advion Biosciences, Ithaca, NY, USA) operating in the positive ion mode. External calibrations were generated from the multiple charged ions produced by a $2 \mu \mathrm{M}$ horse heart myoglobin solution diluted in a $1: 1(\mathrm{v} / \mathrm{v})$ water:acetonitrile mixture acidified with $1 \%$ $(\mathrm{v} / \mathrm{v})$ formic acid, and caesium iodide clusters diluted to $2 \mathrm{~g} / \mathrm{L}$ in a 1:1 (v/v) water:isopropanol solution. Intact masses of anti-HER2 VHHs were first determined in denaturing conditions by diluting the samples to $2 \mu \mathrm{M}$ in a $1: 1(\mathrm{v} / \mathrm{v})$ water/acetonitrile mixture acidified with $1 \%(\mathrm{v} / \mathrm{v})$ formic acid. Native protein analysis in non-denaturing conditions was then performed by diluting samples to $5 \mu \mathrm{M}$ in $100 \mathrm{mM} \mathrm{NH} 4 \mathrm{Ac}$

242 buffer at $\mathrm{pH}$ 7.5. Fine-tuning of instrumental parameters was notably applied to preserve native 3D 
243 structures in the gas phase and ensure efficient ion desolvation and transmission. Particularly, the Synapt

244 G2-S source back-pressure was equal to 4.5 mbar while the acceleration voltages applied on the sample

245 cone as well as in the trap cell were set to 40 and $4 \mathrm{~V}$, respectively. Data processing was finally carried out

246 on MassLynx V4.1 (Waters, Manchester, UK).

2472.10 Native $H D X-M S$. The protocol was similar to those previously described in native MS, except that $248 \mathrm{D}_{2} \mathrm{O}$ incubations were triggered by a 20-fold dilution of $\mathrm{NH}_{4} \mathrm{Ac}$ buffer-exchanged anti-HER2 VHH 249 samples in the same but deuterated $100 \mathrm{mM} \mathrm{NH}_{4} \mathrm{Ac}$ buffer at $\mathrm{pD} 7.5$ before infusion $(95 \%$ final deuterium 250 content). Mixtures were prepared in triplicates and analyzed by native MS in rigorously identical 251 conditions, across an incubation time window ranging from 1 minute to 1 hour. Instrumental conditions 252 were slightly refined (sampling cone and trap acceleration voltages respectively raised to 150 and $20 \mathrm{~V}$ ) to 253 achieve a complete ion desolvation required for accurate deuterium uptake measurements.

2542.11 Ion-mobility mass spectrometry (IM-MS). IM-MS experiments were performed on the 255 abovementioned mass spectrometer. Fine-tuning of the instrument enabled to achieve a good trade-off 256 between native ion preservation, desolvation, separation and TWIMS resolution. Low accelerating 257 voltages were used, especially before IM separation, to guide the ions through the mobility cell to the TOF 258 analyzer without ion activation. Specifically, the Synapt G2-S source back pressure and sampling cone 259 voltage were equal to $5.1 \mathrm{mbar}$ and $20 \mathrm{~V}$, respectively. The argon flow rate and the collision energy inside 260 the ion trap cell were fixed to $2.5 \mathrm{~mL} / \mathrm{min}$ and $5 \mathrm{~V}$, respectively. Prior to IM separation, ions were 261 thermalized in the helium cell $(140 \mathrm{~mL} / \mathrm{min})$. Ion separation was performed in the pressurized ion mobility 262 cell using a constant $\mathrm{N}_{2}$ flow rate of $30 \mathrm{~mL} / \mathrm{min}$. The IM wave height and velocity were respectively set to $26335 \mathrm{~V}$ and $1334 \mathrm{~m} / \mathrm{s}$. Transfer collision energy was fixed to $2 \mathrm{~V}$ to extract the ions from the IM cell to the 264 TOF analyzer. Arrival time distributions (ATDs) and collisional cross sections $\left({ }^{\mathrm{TW}} \mathrm{CCS}_{\mathrm{N} 2 \rightarrow \mathrm{He}}\right.$ ) of oxidized 265 and reduced $8^{+}$ions were extracted and determined in their native (Trap CE $=5 \mathrm{~V}$ ) and gas-phase 266 activated conformations (Trap CE $=15$ and $60 \mathrm{~V}$ ) using an appropriate IM calibration (cytochrome-c and $267 \beta$-lactoglobulin native ions used as external calibrants [40,41]). Drift time $\left(t_{\mathrm{D}}\right)$ and ${ }^{\mathrm{TW}} \mathrm{CCS}_{\mathrm{N} 2 \rightarrow \mathrm{He}}$ values for 268 each conformer were finally expressed as an average measured in triplicate on the $8^{+}$charge state.

2692.12 Collision induced unfolding (CIU) experiments. ATDs were recorded in triplicate by gradually 270 increasing the trap collision energy in the traveling-wave-based ion trap before the IM cell. All the ions 271 were accelerated into the ion trap without any previous selection. However, only ion mobility data 272 corresponding to the $8+$ charge state of studied samples were compiled to create the averaged CIU 273 fingerprints. The trap collision energy was ramped from 0 to $120 \mathrm{~V}$ using an energy interval of $5 \mathrm{~V}$. This 274 voltage interval corresponds to the best trade-off between CIU fingerprint resolution and acquisition time. 275 2D CIU fingerprint plots were analysed using the open source CIUSuite software, especially the 
276 CIUSuite_stats and CIUSuite_compare modules [42]. Briefly, these modules allow for drift time data 277 extraction at each trap collision energy (trap CE). Ion intensities were normalized to a maximum value of 2781 and the ATDs were smoothed using a Savitzky-Golay filter with a window length of 3 and a polynomial 279 order of 2. The individual IM data were gathered to create the CIU data shown. Drift time (ms) is shown 280 in the $y$-axis versus trap collision energy (V) in the $x$-axis. The relative intensities of the ATD 281 distributions are denoted by a color-coded axis. CIU fingerprint plots and standard deviations were 282 generated for three replicates using CIUSuite_stats function to quantify the reproducibility of the 283 experiment. Comparison of 2 different CIU fingerprint plots was achieved using the CIUSuite_compare 284 module. 


\section{Results:}

2883.1 Production of VHHs, purity and disulfide bridge homogeneity assessment. The model used in this 289 study is the anti-HER2 VHH 11A4 to which we have added a poly-His tag at the C-terminus. This VHH 290 has been widely described and produced in bacteria system [32]. The periplasmic localization peptide signal sequences, such as $O m p A$ or $P e l B$, were systematically used to direct the produced VHH in an oxidative environment for the formation of the expected disulfide bridge (see Figure 1, for detailed sequences of the different VHHs used). We produced the anti-HER2 VHH in E. coli BL21(DE3) strain with or without the alternative periplasmic peptide signal sequence, $P e l B$, to evaluate its impact on the production yield compared to the classically used $O m p A$ sequence, as well as on the disulfide bridge formation. The results are presented in Figure 2. First, we obtained about 1 to $10 \mathrm{mg} / \mathrm{L}$ of purified proteins from periplasmic ( $O m p A$ or $P e l B)$ and cytosolic expressions, respectively (Table 1), suggesting that the periplasmic signal sequence PelB from the pET20b vector does not affect the expression of VHHs. The SDS-PAGE analysis of the final products demonstrates the purity of the anti-HER2 VHH and gives some information on the disulfide bridge presence. First of all, a well-defined band with an apparent molecular weight of $14 \mathrm{kDa}$ is commonly observed for each preparation, confirming sample purity. As expected, the production in the periplasmic space (PS) results in a clear shift of the migration distance between non-reducing and reducing conditions and thus, indicates the presence of the disulfide bridge upon periplasmic expression, while not formed in the cytosolic space (Cyto, Figure 2A). To maintain both of these favourable conditions (high production yield and disulfide bridge formation), we chose to produce this VHH in the bacterial strain Shuffle T7 (Shu) capable of protein disulfide bond formation in its cytoplasm as described for other proteins [43]. As shown in Table 1, the production yield of the Shuffle $T 7$ strain remained expectedly high $(\approx 10 \mathrm{mg} / \mathrm{L})$ compared to the cytosolic expression in the E.coli BL21(DE3) strain. In Figure 2A, however, the "Shu" gel lane does not show a significant band shift between non-reducing and reducing conditions. This NR band is more diffuse than in the cytosolic and periplasmic samples, indicating a potential mixture of disulfide bonded and non-bonded species. Alternatively, VHHs can also be expressed in inclusion bodies (IB) to increase their production yield [44]. The main downside of this approach is that this production mode necessitates subsequent refolding steps, which can affect the protein ternary structure and potentially induce undesired chemical modifications. However, these constraints are counterbalanced by a gain in production yield. We thus produced another batch of anti-HER2 VHH in BL21(DE3) using high expression conditions (Magic Media®). The protein was directly purified under denaturing condition (6 M guanidine) and refolded with an optional oxidation step in the presence of the redox GSSG/GSH couple. We refined the refolding process described by Dagar 
et al [45] for the screen of buffers and added a preliminary oxidation step by bringing a reduced and oxidized glutathione mixture (10:1 ratio) to form the disulfide bridge. We adapted the refolding process described by Tsumoto et al [46] by adding high concentration of L-Arginine (1 M) during the refolding steps. Subsequent purification enabled us to isolate two refolded fractions (Figure $\mathbf{2 A}$, lines RO and RR respectively). Markedly, these conditions led to a 10 fold production yield increase compared to the reference cytosolic conditions and thus represent a beneficial solution for the production of large amounts of the desired protein (see Table 1 for further details). We obtained a high refolding yield of nearly $90 \%$ and $75 \%$ for the oxidized and reduced conditions, respectively. The band shift upon reduction was observed on the SDS-PAGE gel for the RO sample but not for the RR sample, indicating respectively the presence and absence of the disulfide bridge (Figure 2A, lines RO and RR).

329

Based on these trials, we also produced two other VHHs in the Shuffle T7 E. coli strain, namely the antiHSA [29] and the anti-EGFR1 [25] which share a high framework sequence homology with the antiHER2 (see Figure 1 for sequence details). The main difference lies in the length of their CDR regions, particularly the CDR3. Contrarily to the anti-HER2 VHH, the clear migration shift observed between reducing and non-reducing gel analyses of the anti-EGFR1 VHH strongly suggested the formation of the disulfide bond (Figure 2B). Conversely, such a shift was not observed for the anti-HSA VHH, hypothesizing that the S-S bond was not formed under these ad hoc conditions (Figure 2C).

3.2 Size exclusion chromatography with multi-angle light scattering analysis (SEC-MALS). The disulfide bridge is an important key lock for the $\beta$-sheet stabilization of VHH structures. It can then impact the VHH recognition and affinity properties for its target. Before looking more precisely into this matter, the VHHs of the present work were all characterized by SEC-MALS in order to assess their homogeneity and size distribution under non-denaturing conditions (Figure 3). SEC chromatograms of anti-EGFR1 and anti-HSA VHHs displayed a unique symmetrical peak confirming sample purity and homogeneity (Figure 3G). All the anti-HER2 chromatograms except the RR sample also showed a unique and symmetrical elution peak (Figures 3A, 3B, 3C, 3D and 3F). The RR sample evidenced a small shoulder preceding the monomeric elution peak that might be due to a dimerization of the protein (Figure 3E). MALS molecular weight calculations based on RI and UV signals give similar results, as summarized in Table 2. Although slightly over-estimated, the molecular weights calculated are in the range of the theoretical molecular weights determined from the primary sequence of each $\mathrm{VHH}$. analysis. To get a more comprehensive picture of the samples' homogeneity and purity, LC-UV-MS 350 experiments were performed. This conventional technique affords to separate and quantify 351 hydrophobically resolved species, before identifying them from their denatured intact mass measurements. 
Anti-HER2 VHH samples were first characterized (Figures $4 \mathbf{A}$ to $\mathbf{4 F}$ and Table 3). Periplasmic and cytoplasmic VHHs were shown to be the most homogeneous samples, LC-UV chromatograms revealing a predominant species eluted at $20.1 \mathrm{~min}$ (97\% abundance) or $21.3 \mathrm{~min}(86 \%)$ which corresponds to the oxidized $(14153.1 \pm 0.3 \mathrm{Da})$ or the reduced form $(14155.0 \pm 0.1 \mathrm{Da})$ of the anti-HER2 VHH (theoretical average mass: 14155.8 Da, assuming no SS bridge and N-terminal Met), respectively (Figures 4A and 4B). Interestingly, the disulfide state could also be addressed by LC because the SS bridge led to a significant hydrophobicity decrease in denatured and oxidized anti-HER2 VHH fractions (-1.2 min of retention time), potentially due to additional constraints induced in their solvent-accessible surface. This enables to separate them from denatured and reduced fractions under the baseline. Furthermore, a significant proportion of oxidized forms (13\% abundance) was also detected in the cytoplasmic sample, while reduced forms appeared to be negligible in the periplasmic sample $(2 \%)$. Finally, traces of extraoxidation ( $1 \%$ ) occurring on both redox and main forms were concomitantly detected in the cytoplasmic (14170.6 $\pm 0.3 \mathrm{Da}, 21.1 \mathrm{~min})$ and the periplasmic sample (14169.2 $\pm 0.3 \mathrm{Da}, 19.9 \mathrm{~min})$. Shu sample appeared to be much more heterogeneous than the two previous ones (Figures $\mathbf{4 C}$ and $\mathbf{4 F}$ ). Indeed, a higher mixture of the abovementioned oxidized (14152.9 $\pm 0.2 \mathrm{Da}, 23 \%$ abundance) and reduced $(14155.1 \pm 0.2 \mathrm{Da}, 56 \%)$ fractions was detected at the same retention times. More preoccupying, additional variants were unexpectedly observed and associated to formylated forms of reduced $(14183.0 \pm$ 0.1 Da, $15 \%$ abundance, 22.5 min retention time) and oxidized anti-HER2 VHHs (14181.0 $\pm 0.3 \mathrm{Da}, 5 \%$ abundance, $21.0 \mathrm{~min}$ ), and to a hypothetical GSH adduct form of the reduced VHH (14284.1 $\pm 0.2 \mathrm{Da}, 1$ $\%$ abundance, $22.1 \mathrm{~min}$ ). Such modifications were also found in RO and RR samples of similar heterogeneity (Figures 4D and 4E). First of all, and similarly to periplasmic and cytoplasmic batches, a high redox homogeneity was found in each sample. Indeed, RO is mainly composed of oxidized antiHER2 VHHs (14153.0 $\pm 0.2 \mathrm{Da}, 66 \%$ abundance) with only traces of reduced fractions $(14154.9 \pm 0.2$ VHHs (14155.1 $\pm 0.2 \mathrm{Da}, 74 \%$ ) and only traces of oxidized fractions (14153.9 $\pm 0.1 \mathrm{Da}, 4 \%$ ) (Figure 4E and Table 3). However, these main redox states also included modified anti-HER2 VHH forms: extraoxidation and formylation from RO $(14168.8 \pm 0.1 \mathrm{Da}, 2 \%$ abundance and $14181.0 \pm 0.3 \mathrm{Da}, 30 \%)$, but also from RR (14170.7 $\pm 0.2 \mathrm{Da}, 2 \%$ and $14183.1 \pm 0.2 \mathrm{Da}, 20 \%)$, respectively. Anti-HSA and EGFR1 VHHs were next LC-UV-MS probed to be compared to anti-HER2 VHH also produced in Shuffle T7 E. coli (Figures 4F, 4G and 4H and Table 3). Contrarily to anti-HER2, anti-HSA and anti-EGFR1 VHH samples appeared highly homogeneous, both from the disulfide state and the post-translational modifications (PTM) side. Indeed, LC-UV chromatogram from anti-HSA VHH sample depicted a main (89\% abundance) and a minor species (11\%), eluted at 21.2 and $21.8 \mathrm{~min}$, and corresponding to the free oxidized form $(12990.0 \pm 0.4 \mathrm{Da})$ and a hypothetical GSH adduct form $(13119.2 \pm 0.3 \mathrm{Da})$ of the anti- 
HSA VHH (theoretical average mass: 12992.5 Da, assuming no SS bridge and a N-terminal Met), respectively (Figure 4G and Table 3). Besides behaving as a fully oxidized sample, anti-EGFR1 also showed to be PTM free, as suggested by the unique LC-UV species detected at $22.4 \mathrm{~min}$ and associated to the oxidized form $(15295.2 \pm 0.1 \mathrm{Da})$ of the anti-EGFR1 VHH (theoretical average mass: 15297.9 Da, assuming no SS bridge and N-terminal Met) (Figure $4 \mathbf{H}$ and Table 3). Interestingly here, hydrophobicity of oxidized and unmodified forms from these 3 denatured VHHs (HER2 $<$ HSA $<$ EGFR1) did not exactly follow their measured average masses (HSA < HER2 < EGFR1), suggesting a strong hydrophobic contribution of the less-conserved CDR3 domain notably between HER2 and HSA.

3.4 Binding properties analysed by surface plasmon resonance (SPR). Once the homogeneity and purity of these VHHs has been assessed, we wanted to measure the affinity of these proteins for their respective "antigens" and to compare it to already available data: anti-HER2 (1.9 nM) [30]; anti-HSA (17 nM) [29]; anti-EGFR (14 nM on cells) [47]. Surface plasmon resonance (SPR) measurements revealed that all VHHs presented a good affinity for their corresponding target with respective Kds of $11.3 \mathrm{nM}, 4.8 \mathrm{nM}$ and about $1 \mathrm{nM}$ for anti-HSA, anti-EGFR1 and anti-HER2 VHHs (see Table 4 for details, and Figure 5 for sensorgram examples). SPR analyses also enabled to determine binding kinetics, notably the association $\left(\mathrm{k}_{\mathrm{on}}\right)$ and dissociation rates $\left(\mathrm{k}_{\mathrm{off}}\right)$ for each VHH. Herein, the anti-EGFR1 VHH associates more slowly with its target $\left(\mathrm{k}_{\mathrm{on}} \approx 2.10^{5} \mathrm{M}^{-1} \mathrm{~s}^{-1}\right)$ than anti-HER2 VHH $\left(\mathrm{k}_{\mathrm{on}} \approx 4.10^{6} \mathrm{M}^{-1} \cdot \mathrm{s}^{-1}\right)$ and anti-HSA VHH $\left(\mathrm{k}_{\mathrm{on}} \approx 8.10^{5}\right.$ $\left.\mathrm{M}^{-1} \cdot \mathrm{s}^{-1}\right)$, but also dissociated more slowly $\left(\mathrm{k}_{\mathrm{off}} \approx 9.10^{-4} \mathrm{~s}^{-1}\right)$ than the two others $\left(\mathrm{k}_{\text {off }} \approx 4.10^{-3}\right.$ and $9.10^{-3} \mathrm{~s}^{-1}$, respectively). Interestingly, all the anti-HER2 VHHs exhibit similar $\mathrm{k}_{\text {on }}$ and $\mathrm{k}_{\text {off }}$ parameters, suggesting that in-mixture micro-heterogeneous forms previously depicted (disulfide bridge, PTMs), would not significantly modify binding properties.

3.5 Secondary structure analysis by circular dichroism. The high conservation of the immunoglobulin Vh domain scaffold is mainly based on a $\beta$-sheet stabilized by the canonical disulfide bridge, which can be easily observed by circular dichroism (CD). CD spectra were thus recorded for each VHH (Figures 6A and 6B). As expected, CD spectra of the different anti-HER2 formats (Figure 6A), anti-HSA and antiEGFR1 VHHs (Figure 6B) shared a common spectral feature characterized by a negative ellipticity signal around $210-220 \mathrm{~nm}$ and corresponding to a $\beta$-sheet motif. However, all anti-HER2 VHHs also displayed an additional negative signal around $230 \mathrm{~nm}$, reported as a distorted $\beta$-sheet signature and representing a singular particularity of this VHH compare to the others [48]. CD data sets were next processed using BeStSel (Beta Structure Selection), an online software which enables to calculate the proportion of each secondary structure $[49,50]$. The results are summarized in Table 5. Accordingly, the anti-HSA VHH would be composed of antiparallel $\beta$-sheet $(64.5 \%)$, turn $(13.5 \%)$ and other structures $(22 \%)$. Antiparallel $\beta$-sheets would thus mostly contribute to the structure of this VHH comprising short CDR 
domains ( $22 \%$ of other structures) and would be subdivided into left-twisted (16\% of antiparallel $\beta$-sheet content), relaxed (35\%) and right-twisted $\beta$-sheets (49\%). Secondary structures would be more complex for anti-EGFR1 VHH due to longer CDR3 domains, but still dominated by antiparallel $\beta$-sheets (47.6 \%) followed by other structures $(45.6 \%)$, turns $(6 \%)$ and $\alpha$-helices $(0.8 \%)$. These results are in agreement with the crystal structure of this protein (PDB entry: $4 \mathrm{KRN}$ ), which notably reveals a distorted $\alpha$-helix inside the CDR3 loop [51] and a simulated CD spectrum matching our experimental data (data not shown). Again, the antiparallel $\beta$-sheets of the anti-EGFR1 VHH would be made of left-twisted (17.6 \% of the antiparallel $\beta$-sheet structure), right-twisted (28.8\%) and relaxed $\beta$-strains (53.6 \%). Anti-HER2 VHHs CD spectra clearly differed from the two others by a distorded $\beta$-sheet contribution at $230 \mathrm{~nm}$. BeStSel analysis suggested that these anti-HER2 VHHs would include $58.3 \%$ of antiparallel $\beta$-sheets, 1.7 $\%$ of parallel $\beta$-sheets, $10.1 \%$ of turns and $29.9 \%$ of other structures. Contrary to the two other VHHs, this predicted parallel $\beta$-sheet part could explain the distortion of the $\beta$-sheet structure leading to the additional CD signal at $230 \mathrm{~nm}$. The antiparallel $\beta$-sheet content would herein split into left-twisted $\beta$ strain $(21.6 \%)$, relaxed (32\%) and right twisted $\beta$-strains $(46.7 \%)$. Interestingly, anti-HSA and antiHER2 VHHs would rather be composed of right-twisted antiparallel $\beta$-strains, while the anti-EGFR1 VHH would essentially be made of relaxed antiparallel $\beta$-strains.

3.6 Thermal stability analysis. Two orthogonal techniques were here applied to determine the thermal stability of native 3D structures from each $\mathrm{VHH}$ : circular dichroism and differential scanning fluorimetry 437 (DSF), which enables to track any change of secondary structure (Figures $\mathbf{6 C}$ to $\mathbf{6 H}$ ) or intrinsic 438 tryptophan fluorescence (Figure 7). CD spectral signatures of each VHH (signals at 217 and $232 \mathrm{~nm}$ for 439 anti-HER2, $217 \mathrm{~nm}$ for anti-EGFR1 and 220nm for anti-HSA) were first monitored to calculate their half440 denaturation temperatures (Tm) (Table 6). As expected, anti-HER2 VHHs enriched with the SS-forms 441 (PS and RO, Figures 6C, 6F and 6I) displayed a higher Tm (around $66{ }^{\circ} \mathrm{C}$ ) than SH-enriched forms 442 (around $55{ }^{\circ} \mathrm{C}$ for Cyto and Shu, Figures 6D, 6E and 6I). This structural stability, improved by the 443 presence of the disulfide bridge in anti-HER2 VHHs, was equivalent in the SS-enriched anti-EGFR1 VHH $444\left(\mathrm{Tm} \approx 66^{\circ} \mathrm{C}\right.$, Figure 6G and 6I). Unexpectedly, such stability was not found in the fully oxidized anti445 HSA VHH, showing a Tm similar to those of anti-HER2 reduced forms $\left(\mathrm{Tm} \approx 55^{\circ} \mathrm{C}\right.$, Figure $6 \mathbf{H}$ and $\left.\mathbf{6 I}\right)$.

446 DSF-based stability studies evidenced two kinds of fluorescence profiles, depending on the type of VHH 447 considered. On the one hand, the anti-HSA VHH experienced an expected fluorescence increase as 448 function of the temperature. It translates a growing tryptophan solvent exposition due to protein 449 denaturation (Figure 7G). On the other hand, for both anti-EGFR1 (Figure 7F) and anti-HER2 VHHs 450 (Figures 7A to 7E), a fluorescence decrease was observed as a function of the temperature. This was 451 atypical but could be here explained by the presence of a tryptophan in the CDR2 or CDR3 loop of anti- 
EGFR1 and anti-HER2 VHHs, respectively. Following this hypothesis, solvent-exposed tryptophans from CDR loops would first result in a high fluorescence signal at low temperature which would then decrease with protein aggregation upon heating. Thermal stability data thereby obtained from DSF analyses of antiHSA and anti-EGFR1 VHHs were in line with CD results and respectively showed a $\mathrm{Tm}$ of about $59{ }^{\circ} \mathrm{C}$ and $68{ }^{\circ} \mathrm{C}$ (Table 6, Figures 7G and 7F). A two-step curve of fluorescence decrease was then measured for Cyto, Shu and RR samples of the anti-HER2 VHH (Figures 7B, 7C and 7E). The first curve was associated with the highest fluorescence drop and displayed an inflection point or $\mathrm{Tm}$ of around $58{ }^{\circ} \mathrm{C}$, close to those obtained by $\mathrm{CD}$ on these same samples $\left(55^{\circ} \mathrm{C}\right.$, Figures $6 \mathrm{D}$ and $6 \mathbf{E}$, Table 6). The inflection point of the second curve revealed another Tm of around $73{ }^{\circ} \mathrm{C}$ similar to those deduced from the CD analyses of fully oxidized anti-HER2 and anti-EGFR 1 samples $\left(70\right.$ and $66{ }^{\circ} \mathrm{C}$, Figures $\mathbf{6 C}$, $\mathbf{6 F}$ and $\mathbf{6 G}$, Table 6). Identification of two concomitant Tm values from the above-mentioned DSF studies was however consistent since these samples have been shown to contain a significant mixture of oxidized and reduced VHH forms (Figure 4 and Table 3). Taking their respective UV proportions into account, DSF proved to be sensitive enough to unravel such redox mixtures. In contrast, PS and RO samples of the antiHER2 VHH presented a single-step curve of fluorescence decrease, corresponding to a unique Tm of around $73{ }^{\circ} \mathrm{C}$ (Figures 7A and 7D). Again, DSF data corroborated $\mathrm{CD}$ values $\left(70{ }^{\circ} \mathrm{C}\right.$, Table 6) and confirmed the redox homogeneity of these two samples, mostly detected under disulfide bridged forms by LC-MS (Figure 4 and Table 3).

3.7 Native mass spectrometry investigation of anti-HER2 VHH intact structures. In order to get structural insights into anti-HER2 VHHs and to better understand how the disulfide bridge can affect their native 3D structures, native MS was performed. This approach, suited to study non-covalent complexes of 473 biomolecules in the gas phase, has also proved to be sensitive to the solvent accessible surface area 474 (SASA) of in-solution native proteins, enabling to probe their overall folding or induced conformational 475 changes through the charge state distribution (CSD) of their native ions [52-55]. Native MS experiments were here focused on periplasmic and cytoplasmic anti-HER2 VHH samples, previously shown to be the most homogeneous representatives of disulfide bridged or unbridged forms, respectively. MS spectra obtained in non-denaturing conditions were thus compared to those generated in denaturing conditions from these two samples (Figure 8). Denaturing MS analyses of infused periplasmic and cytoplasmic samples first corroborated LC-UV-MS data, leading to the single detection of the most abundant oxidized $(14153.5 \pm 0.1 \mathrm{Da})$ or reduced $(14155.4 \pm 0.1 \mathrm{Da})$ forms, respectively (Figure 8A). In addition to the average mass measurements, the redox state of these two denatured species could also be deduced from the isotopic distribution of their related ions (Figure 8A inset). Indeed, comparing the isotopic distribution of similarly charged ions observed in denaturing MS analyses of both oxidized and reduced forms $\left(11^{+}\right.$herein), enabled to systematically evidence a 2 Da mass shift resulting from the disulfide state. 
Moreover, such observations also led to notice that CSDs resulting from these two denatured redox species strongly differed: the oxidized form displayed a broad CSD shifted towards higher $\mathrm{m} / \mathrm{z}$ ratios (i.e. lower charge states $\mathrm{z}$, ranging from $6^{+}$to $12^{+}$) and centered on the $8^{+}$charge state, while the reduced form exhibited a broad CSD shifted towards lower $\mathrm{m} / \mathrm{z}$ ratios (i.e. higher charge states $\mathrm{z}$, ranging from $6^{+}$to $16^{+}$) and centered on the $13^{+}$charge state. These CSD differences suggest that solvent accessibility of basic residues exposed at the surface of these denatured VHHs and prone to ionisation, that is the SASA, would decrease upon SS bridging. In other words, denatured and oxidized species would display a more

493

494 compact conformation (lower SASA) than denatured and reduced species, in agreement with their differences of hydrophobicity observed by LC-UV-MS. Periplasmic and cytoplasmic samples were then analysed under non-denaturing conditions by native MS (Figure 8B). Except from additional species linked to non-covalent and unspecific acetate adducts $(+62 \mathrm{Da})$, oxidized and reduced forms were anew detected under the same masses $(14153.4 \pm 0.1 \mathrm{Da}$ and $14155.3 \pm 0.1 \mathrm{Da}$, respectively) and could still be differentiated using isotopic distributions of their native ions (Figure 8B inset). However, CSD differences pinpointed in denaturing MS were no longer observed in native MS. Indeed, each redox species provided a similar and narrower CSD, shifted towards higher $\mathrm{m} / \mathrm{z}$ ratios (i.e. lower charge states $\mathrm{z}$, only ranging from $6^{+}$to $8^{+}$) and centred on the $7^{+}$charge state. Altogether, these data first confirm that SASA of both oxidized and reduced species decrease from denaturing to native conditions, in agreement with the preservation of native-like structures $[52,53,55]$. But more importantly, the fact that oxidized and reduced forms share an identical CSD in native MS would mean that these two species adopt a similar native structure. Accordingly, the disulfide bridge would not significantly impact anti-HER2 VHH native folding, as suggested by the SEC-MALS and CD data.

3.8 Structural impact of the disulfide bridge in anti-HER2 VHHs assessed by native HDX-MS. An alternative method to promptly and globally probe the structural impact of the disulfide bridge in antiHER2 VHHs was to combine native MS with hydrogen/deuterium exchange (HDX). In brief, the ability of amide hydrogens from native protein backbones to exchange with ambient deuterium typically serves as a sensor to track structural and dynamic features of protein complexes [56-58]. This property, linked to solvent accessibility and secondary structures, is commonly addressed from protein to peptide level by MS and has been widely used to decipher folding state and partner binding modes of various protein classes [59-63]. Despite less resolutive, native HDX-MS constitutes an original quench and LC-free approach to additionally probe H/D exchange of side chain labile hydrogens while circumventing potential online digestion and subsequent peptide fractionation bottlenecks [64-66]. In this context, anti-HER2 VHH represents a 127-residue protein containing a total of 243 labile hydrogens (120 on the side chains and termini, 123 on the amide backbone) in its neutral form (Figure 1). Since a disulfide bridge implies the loss of two exchangeable hydrogens in both cysteines side chains involved in the bridge, only deuterium 
uptake differences significantly higher than $4 \mathrm{Da}$ could be interpreted as the result of structural and/or dynamic changes between the two redox forms. Due to the depletion of PS sample stock, such experiments were thus performed between RO and Cyto batches, respectively shown to be mostly oxidized and reduced in LC-UV-MS (Figure 9 and Table 7). Native MS analyses of unlabeled oxidized (RO, Figure 9A) and reduced forms (Cyto, Figure 9D) confirmed the detection of two single species sharing the same $7^{+}$-centered CSD but differing from each other by $2 \mathrm{Da}$ (Table 7, $14153.8 \pm 0.3$ and $14155.4 \pm 0.1 \mathrm{Da}$, respectively). Extra-formylated forms were also observed in the oxidized VHH sample (Figure 9A inset, $14181.7 \pm 0.3 \mathrm{Da}$ ), increasing MS spectrum heterogeneity and corroborating LC-UVMS data. Incubating each redox form in $\mathrm{D}_{2} \mathrm{O}$ from $1 \mathrm{~min}$ (Figure 9B and 9E) to $1 \mathrm{~h}$ (Figure 9C and 9F) led to a significant but constant mass uptake over time (Table 7): unlabeled and oxidized VHH signals were shifted towards higher average masses of $14301.8 \pm 2.1$ (1min, Figure 9B) and $14302.9 \pm 1.2 \mathrm{Da}$ (1h, Figure 9C), while unlabeled and reduced VHH signals were displaced towards higher average masses of $14304.6 \pm 1.0$ ( 1 min, Figure 9E) and 14305.0 $\pm 1.3 \mathrm{Da}(1 \mathrm{~h}$, Figure 9F). Interestingly, this global deuterium uptake of around $150 \mathrm{Da}$, appeared limited regarding the number of available labile hydrogens (243, i.e. $62 \%$ ) and did not markedly progress along the labeling time, suggesting either a rigid and tightly folded anti-HER2 VHH scaffold or in-source back exchange [65]. More importantly, no significant differences could be depicted here between average deuterium uptake curves of oxidized and reduced forms of anti-HER2 VHH (Table 7). Note however that any potential in-source back exchange could be here non-reproducible (since occurring on non-denatured ion species) and hide existing uptake differences, which is very unlikely and not considered here. Further comparison of isotopic distributions behind charge states of each redox form was unfortunately hampered by overlapping signals from extraformylated forms. Altogether, these data also support a negligible effect of the disulfide bridge in the antiHER2 VHH structure.

3.9 Gas-phase structure and stability of anti-HER2 VHHs probed by native IM-MS and CIU experiments.

544 Another way to explore anti-HER2 VHH intact structures and investigate to which extent the disulfide 545 bridge can affect them, consisted into coupling native MS with ion mobility (IM). This additional gas546 phase dimension, enabling to separate native ions according to their charge but also to their shape, was 547 shown to be a valuable way to assess intact conformations of proteins and their non-covalent assemblies 548 [67-69]. As already described, native IM-MS experiments were carried out on periplasmic and cytoplasmic samples. Arrival time distributions (ATDs), corresponding here to the time spent by oxidized and reduced native ions to drift across the ion mobility cell, were pairwise compared on each common charge state (namely from $6^{+}$to $8^{+}$, see Figure $\mathbf{8 B}$ ) and thus used as a direct mean to compare their respective gas phase conformations (Figure 10 A). Indeed, for a given charge state, the more extended the 
will be. Accordingly, injecting oxidized (PS) and reduced (cyto) native ions of similar charge states in the IM cell under soft energy conditions (trap collision energy $=5 \mathrm{~V}$ ), systematically provided similar ATDs, as shown on the $8^{+}$charge state with average drift times $\left(t_{D}\right)$ centered on $5.62 \pm 0.00 \mathrm{~ms}$ and $5.69 \pm 0.06$ ms, respectively (Figure 10A top panel and Table 8). Using an appropriate IM-MS calibration [40], these drift time values could be converted into collision cross sections $\left({ }^{\mathrm{TW}} \mathrm{CCS}_{\mathrm{N} 2 \rightarrow \mathrm{He}}\right.$, as referred to in Gabelica et al [41]) which also showed to be similar for each charge state, as depicted between $8^{+}$oxidized (14.56 \pm $\left.0.04 \mathrm{~nm}^{2}\right)$ and reduced $\left(14.62 \pm 0.09 \mathrm{~nm}^{2}\right)$ native ions. Brought together, native IM-MS analyses of oxidized and reduced native ions suggest here that these two redox species would yet display a similar native conformation, in agreement with previous native MS, SEC-MALS and CD studies.

Native IM-MS can hence provide access to the global conformation of biological systems in the gas-phase but generally suffers from a limited resolution, rendering detection of subtle conformational changes tricky [70-72]. However, this instrumental bottleneck can sometimes be circumvented by monitoring ion conformations from their native state(s) to their activated state(s) through a collision induced unfolding (CIU) step performed in the gas-phase [73]. Besides giving insights into ion conformational stability, this alternative can also help to resolve two undistinguishable native conformations evolving however towards IM-distinguishable conformational intermediates and has already been applied with success to various protein complexes [74-76]. Such studies are typically led by first submitting ions to growing collisional energies in the trap cell before separating them in the IM cell. CIU experiments were thus performed on the neighbouring oxidized and reduced conformations of anti-HER2 VHH, and more particularly on their $8^{+}$charge state, selected on the basis of its intensity and its propensity to unfold in the gas phase (Figures 10A middle and bottom panels, 10B and Table 8). To that end, oxidized and reduced $8^{+}$native ions from periplasmic and cytoplasmic samples were conformationally pre-activated through a ramp of trap collision energy prior to be injected in the IM cell. Remarkably, their conformational stability profiles showed a significant divergence. Indeed, ATD of $8^{+}$reduced native ions quickly reacted to collisional energy (from $15 \mathrm{~V}$ ), experiencing a fast and large transition toward higher drift times to ultimately reach (from $20 \mathrm{~V}$ ) a $\mathrm{t}_{\mathrm{D}}$ of $7.06 \pm 0.00 \mathrm{~ms}$ and a corresponding ${ }^{\mathrm{TW}} \mathrm{CCS}_{\mathrm{N} 2 \rightarrow \mathrm{He}}$ of $15.69 \pm 0.02 \mathrm{~nm}^{2}$ (Figure 10A middle and bottom panels and Table 8). Such a CIU-based conformational change $\left(+7.3 \%{ }^{\mathrm{TW}} \mathrm{CCS}_{\mathrm{N} 2 \rightarrow \mathrm{He}}\right)$ was however not observed from the native conformation of $8^{+}$oxidized ions. Despite being shifted towards higher drift times over growing collisional energies, ATD of these ions underwent a much more limited transition. Indeed, collisional induced unfolding also started to occur at $15 \mathrm{~V}$ but led to an ultimate less extended conformation after $20 \mathrm{~V}$, as suggested by a $\mathrm{t}_{\mathrm{D}}$ of $6.61 \pm 0.00 \mathrm{~ms}$ and a ${ }^{\mathrm{TW}} \mathrm{CCS}_{\mathrm{N} 2 \rightarrow \mathrm{He}}$ of $15.36 \pm$ $0.02 \mathrm{~nm}^{2}\left(+5.5 \%{ }^{{ }^{T W}} \mathrm{CCS}_{\mathrm{N} 2 \rightarrow \mathrm{He}}\right)$ (Figure 10A middle and bottom panel and Table 8). Tridimensional representation and comparison of CIU fingerprints rendered these two distinct behaviours more concrete (Figure 10B). As described, $8^{+}$oxidized native ions appeared conformationally more stable than the 
588 reduced ones, unfolding at the same collisional energy threshold (Trap CE $=15 \mathrm{~V}$ ) but able to retain a 589 much more compact conformation $\left(\mathrm{t}_{\mathrm{D}} \approx 6.6 \mathrm{~ms}\right)$ than activated reduced forms $\left(\mathrm{t}_{\mathrm{D}} \approx 7.1 \mathrm{~ms}\right)$. To conclude, $5908^{+}$native and PTM free ions extracted from native IM-MS and CIU analyses of RO and RR samples, 591 revealed identical native conformations and CIU fingerprints between RR and Cyto, as well as between 592 RO and PS samples (Figure 10C). The same native conformation was also found for $8^{+}$native and PTM 593 free ions generated from Shu sample while their CIU fingerprint proved here to be a perfect convolution 594 of oxidized and reduced CIU signatures (Figure 10D). Interestingly, relative quantifications based on 595 ATD peak areas extracted from activated conformations of oxidized and reduced species (respectively 33 596 and 67\%, data not shown) in the transition CE window (20-40 V), match those deduced from LC-UV-MS 597 data (respectively 29 and $71 \%$ by only considering these two species).

598 


\section{Discussion:}

600 As previously stated, $\mathrm{VHH}$, the smallest functional part of camelid heavy-chain antibodies, was 601 transformed from a Mother Nature exception into an ingenious way to address diseases [77]. As often in 602 Research, the first steps towards new technologies, beyond the visions nourished by those discoveries on 603 what they can be used for, are the practical considerations that are too often neglected in the first place. 604 Because the therapeutic potential of the antibody area is immense, but also because the technical practicability forms a major obstacle, any extension of that domain towards routes that will simplify the approaches should be welcomed. The general view of the antibody therapy in oncology has been that the proteins per se were only a way to characterize the cancer cells in a physio-pathological environment. It was next suggested that adding one or several cytotoxic compounds to those antibodies would turn them into missile-launching cargos far more effective than previous addressing systems, using a series of proteins that might cover cancer-specific targets, such as kit [78], TIM-1 [79] or guanylyl cyclase C [80] to name only but a few. Then the complexity to obtain such large proteins in industrial quantity, to manipulate and load them, specifically and homogeneously, with cytotoxic compounds turned out to be major problems, sometimes to a point where the project was killed because of practical considerations.

614 The rise of $\mathrm{VHH}$ proteins, with molecular weights in the 12 to $15 \mathrm{kDa}$ range - as opposed to the $150 \mathrm{kDa}$ 615 of antibodies - renders those alternative strategies far more attractive. The benefits of those VHHs have 616 been nicely discussed by van Bockstaele et al [77]. Furthermore, one can also imagine, in view of recent 617 progresses in the chemical synthesis of proteins [81,82], that those proteins can be chemically synthesized. 618 This opportunity would also facilitate the introduction of exotic amino acids that could be linked to 619 cytotoxic compounds using alternative chemistry routes. We recently obtained the first synthetic anti620 HER2 VHH [83], opening a route towards the possibility of using this approach to introduce orthogonal 621 new chemistry to build armed VHHs. Too often as well, the practical evaluation of the characteristics of a

622 given compound, such as innovative (bio)molecules is at first neglected. In the present work, we wanted to 623 assess the technical steps required to understand the way those small proteins were produced, purified and 624 characterized. For this, we designed a workflow that we dissected and benchmarked on three relevant 625 VHHs raised against potential biomarkers in numerous pathologies, namely HSA, HER2 and EGFR1. 626 This pilot study challenged here different modes of bacterial production and showed how these can impair 627 VHH key attributes such as yield, homogeneity, structure and function. It is somewhat surprising that an 628 area of such great potential be too often poorly characterized in terms of biophysical properties, despite beautiful biological data obtained with those objects [84-89]. Therefore, we embarked in a multi-stage characterization process during which model functional VHHs were thoroughly analyzed for their 
631 homogeneity and structures. Attempts were even made to crystalize the anti-HER2 VHH without success 632 despite the 167 VHH structures deposited in the protein Data Bank.

633 Taking advantage of our passed knowledge in protein expression, we addressed the question of the 634 bacteria production of anti-HER2 VHH and set our experiments to compare its behavior with those of

635

636

637

638

639

640

641

642

643

644

645

646

647

648

649

650

651

652

653

654

655

656

657

658

659

660

661

662

663 other similar VHHs (anti-HSA and anti-EGFR1). After having shown that VHHs could be expressed at high purity and quality, it seemed essential to rigorously characterize these recombinant VHHs. Indeed, one should keep in mind that boosting the yield in bacterial production systems enhances the risk to increase the sample heterogeneity. Despite those drawbacks, the whole scheme is amenable to an industrial process, broadening the perspective to commercially propose these proteins. However, it would be advised to avoid refolding strategies for big scale productions, due to potential modifications that can result from such processes. LC-UV-MS experiments have revealed the heterogeneity of VHHs produced in bacteria system in terms of disulfide bridge formation (anti-HER2 VHH: Shu, Cyto) and posttranslational modifications performed in the Shuffle $T 7$ strain and in IB expression system. The periplasmic expression system shows one way to promote VHH production even if the yield is low comparing to cytoplasmic or expression in IB.

As in many other domains, a rigorous quality control is required for the production of proteins aimed at human treatments. As evidenced in the present study, SDS-PAGE appeared insufficient to extensively assess sample purity and homogeneity. Indeed, this approach clearly confirmed the disulfide bridge formation in anti-EGFR1 VHH but led to ambiguous or erroneous interpretations for anti-HER2 and antiHSA VHHs. Such information requires to be investigated with more sophisticated techniques. Among those techniques, LC-UV-MS was proved to be a valuable tool not only to identify but also to quantify hydrophobically fractionated species such as reduced, oxidized and modified forms of anti-HER2 VHH. Thus, the main technique to observe the adequate formation of this bridge would be LC-MS. Furthermore, MS offers the advantage to validate the presence of the desired product, and to assess its purity, while documenting the nature of possible amino acid modifications that could have occurred along the process.

Many efforts have notably been made here to characterize and understand the importance of the disulfide bridge in the overall VHH structure and affinity for its target. The covalent bond was proved to be a key point not only to contribute to $\mathrm{VHH}$ folding but also to maintain its structure. Indeed, the SDS-PAGE clearly indicates the presence of the disulfide bridge as it has been shown for the anti-EGFR1 VHH but it could be more uncertain as for the anti-HER2 VHH or totally false as for the anti-HSA VHH and, by consequence, high resolution techniques should be used to clearly characterize the sample composition. This first part of the data obtained on samples produced in the Shuffle T7 strain indicates that this bacteria strain could be useful for VHH expression in a SS state (anti-HSA and anti-EGFR1 VHHs), although this 
664 competence seems also to depend on the amino-acid sequence of the protein and could lead to additional 665 protein modifications (anti-HER2 VHH). Altogether, these results suggest that the formation of the 666 disulfide bridge is not only related to the oxidative environment during the expression but also to the 667 sequence of the VHH CDRs, despite the close similarity between the three VHH frameworks presented 668 herein. . Interestingly, no significant $\mathrm{Kd}$ differences were observed between the different anti-HER2 669 VHHs, suggesting that the presence of disulfide bridge has a negligible impact on the protein binding 670 ability. Furthermore, the affinity constants of those VHHs were in the range of the corresponding 671 antibodies. VHHs possess a canonical structure comprising a relatively standard scheme, with common 672 features separated by usually 3 variable domains: CDR1, 2 and 3. Briefly, the three VHHs studied here 673 are all composed of 8 residues for the CDR1 with a common GXTFXXF/YX pattern, a CDR2 of 7 or 8 674 residues with very closely related sequences and a highly variable CDR3 (Figure 1). Indeed, the CDR3 of 675 the anti-HSA is only composed of 9 residues while the CDR3 of anti-HER2 and anti-EGFR1 VHHs 676 contain 14 and 20 residues, respectively. It is obvious that those CDRs are responsible for the recognition 677 of the "antigen", with a particular contribution of the larger and less conserved one, CDR3. Altogether, 678 data reported in the present work suggest that these VHHs would share an overall antiparallel $\beta$-sheet 679 structure, but that small differences in their primary sequences and notably in their CDRs, could strongly 680 affect the torsion/orientation state of their respective antiparallel $\beta$-strain. Thus, we believe that these 681 different contributions could be directly linked to the difference of affinity observed between the 3 VHHs 682 and to their ability to form the framework canonical disulfide bridge in the Shuffle T7 E.Coli strain, 683 especially in the case of the anti-HER2 VHH which exhibits an additional distorted $\beta$-sheet signature in its 684 CD spectrum

685 In conclusion, we believe that the quality control of VHHs, whenever they are produced for research or 686 therapeutic use, must be implemented by such means, to ensure their structural and stability properties. 687 Altogether, native MS, HDX-MS, IM-MS and CIU studies first suggest than the disulfide bridge would 688 not alter but strongly stabilize native conformations of anti-HER2 VHHs by covalently locking them, in 689 line with CD and DSF-based stability data. These results also support that the production mode of 690 oxidized and reduced anti-HER2 VHHs would not significantly hamper here their overall structures and 691 stabilities. Finally, native IM-MS and CIU approaches demonstrated to be sensitive enough and with a 692 high resolution capacity to semi-quantitatively address such structural properties inside mixtures of redox 693 forms. To industrialize a VHH as a research or a therapeutic tool, it is really important to identify the 694 contribution of the CDR sequences on the ability to produce high quantity at high quality in an 695 industrialized process and not be only focused on the affinity of this object towards its "antigen". 


\section{References}

698 [1] S. Singh, N.K. Kumar, P. Dwiwedi, J. Charan, R. Kaur, P. Sidhu, V.K. Chugh, Monoclonal Antibodies, Curr Clin Pharmacol 13 (2018) 85-99.

[2] A. Mullard, 2018 FDA drug approvals, Nat Rev Drug Discov 18 (2019) 85-89.

[3] S. Parakh, A.C. Parslow, H.K. Gan, A.M. Scott, Antibody-mediated delivery of therapeutics for cancer therapy, Expert Opin Drug Deliv 13 (2016) 401-419.

[4] M. Chodorge, A.J. Celeste, J. Grimsby, A. Konkar, P. Davidsson, D. Fairman, L. Jenkinson, J. Naylor, N. White, J.C. Seaman, K. Dickson, B. Kemp, J. Spooner, E. Rossy, D.C. Hornigold, J.L. Trevaskis, N.J. Bond, T.B. London, A. Buchanan, T. Vaughan, C.M. Rondinone, J.K. Osbourn, Engineering of a GLP-1 analogue peptide/anti-PCSK9 antibody fusion for type 2 diabetes treatment, Scientific Reports 8 (2018) 17545.

[5] A.H. Laustsen, A. Karatt-Vellatt, E.W. Masters, A.S. Arias, U. Pus, C. Knudsen, S. Oscoz, P. Slavny, D.T. Griffiths, A.M. Luther, R.A. Leah, M. Lindholm, B. Lomonte, J.M. Gutiérrez, J. McCafferty, In vivo neutralization of dendrotoxin-mediated neurotoxicity of black mamba venom by oligoclonal human IgG antibodies, Nature Communications 9 (2018) 3928.

[6] A.C. Chan, P.J. Carter, Therapeutic antibodies for autoimmunity and inflammation, Nat Rev Immunol 10 (2010) 301-316.

[7] A. Markham, Bezlotoxumab: First Global Approval, Drugs 76 (2016) 1793-1798.

[8] A.M. Scott, J.D. Wolchok, L.J. Old, Antibody therapy of cancer, Nat Rev Cancer 12 (2012) 278-287.

[9] G. Elia, T. Fugmann, D. Neri, From target discovery to clinical trials with armed antibody products, J Proteomics 107 (2014) 50-55.

[10] A. Beck, L. Goetsch, C. Dumontet, N. Corvaïa, Strategies and challenges for the next generation of antibody-drug conjugates, Nat Rev Drug Discov 16 (2017) 315-337.

[11] A. Thomas, B.A. Teicher, R. Hassan, Antibody-drug conjugates for cancer therapy, The Lancet Oncology 17 (2016) e254-e262.

[12] T.N. Iwata, C. Ishii, S. Ishida, Y. Ogitani, T. Wada, T. Agatsuma, A HER2-Targeting AntibodyDrug Conjugate, Trastuzumab Deruxtecan (DS-8201a), Enhances Antitumor Immunity in a Mouse Model, Mol Cancer Ther 17 (2018) 1494-1503.

[13] C. Szot, S. Saha, X.M. Zhang, Z. Zhu, M.B. Hilton, K. Morris, S. Seaman, J.M. Dunleavey, K.-S. Hsu, G.-J. Yu, H. Morris, D.A. Swing, D.C. Haines, Y. Wang, J. Hwang, Y. Feng, D. Welsch, G. DeCrescenzo, A. Chaudhary, E. Zudaire, D.S. Dimitrov, B. St Croix, Tumor stroma-targeted antibody-drug conjugate triggers localized anticancer drug release, J Clin Invest 128 (2018) 29272943.

[14] S. Cho, F. Zammarchi, D.G. Williams, C.E.G. Havenith, N.R. Monks, P. Tyrer, F. D’Hooge, R. Fleming, K. Vashisht, N. Dimasi, F. Bertelli, S. Corbett, L. Adams, H.W. Reinert, S. Dissanayake, C.E. Britten, W. King, K. Dacosta, R. Tammali, K. Schifferli, P. Strout, M. Korade, M.J. Masson Hinrichs, S. Chivers, E. Corey, H. Liu, S. Kim, N.H. Bander, P.W. Howard, J.A. Hartley, S. Coats, D.A. Tice, R. Herbst, P.H. van Berkel, Antitumor Activity of MEDI3726 (ADCT-401), a Pyrrolobenzodiazepine Antibody-Drug Conjugate Targeting PSMA, in Preclinical Models of Prostate Cancer, Mol Cancer Ther 17 (2018) 2176-2186.

[15] P. Strop, T.-T. Tran, M. Dorywalska, K. Delaria, R. Dushin, O.K. Wong, W.-H. Ho, D. Zhou, A. Wu, E. Kraynov, L. Aschenbrenner, B. Han, C.J. O’Donnell, J. Pons, A. Rajpal, D.L. Shelton, S.-H. 
Liu, RN927C, a Site-Specific Trop-2 Antibody-Drug Conjugate (ADC) with Enhanced Stability, Is

Highly Efficacious in Preclinical Solid Tumor Models, Mol Cancer Ther 15 (2016) 2698-2708.

[16] P. Polakis, Antibody Drug Conjugates for Cancer Therapy, Pharmacol Rev 68 (2016) 3-19.

[17] Y. Mimura, T. Katoh, R. Saldova, R. O’Flaherty, T. Izumi, Y. Mimura-Kimura, T. Utsunomiya, Y. Mizukami, K. Yamamoto, T. Matsumoto, P.M. Rudd, Glycosylation engineering of therapeutic IgG antibodies: challenges for the safety, functionality and efficacy, Protein Cell 9 (2018) 47-62.

[18] F.S. van de Bovenkamp, N.I.L. Derksen, P. Ooijevaar-de Heer, K.A. van Schie, S. Kruithof, M.A. Berkowska, C.E. van der Schoot, H. IJspeert, M. van der Burg, A. Gils, L. Hafkenscheid, R.E.M.

Toes, Y. Rombouts, R. Plomp, M. Wuhrer, S.M. van Ham, G. Vidarsson, T. Rispens, Adaptive antibody diversification through $\mathrm{N}$-linked glycosylation of the immunoglobulin variable region, Proc Natl Acad Sci U S A 115 (2018) 1901-1906.

[19] G. Husson, A. Delangle, J. O'Hara, S. Cianferani, A. Gervais, A. van Dorsselaer, D. Bracewell, C. Carapito, Dual Data-Independent Acquisition Approach Combining Global HCP Profiling and Absolute Quantification of Key Impurities during Bioprocess Development, Anal. Chem. 90 (2018) 1241-1247.

[20] A. Skerra, Alternative non-antibody scaffolds for molecular recognition, Curr Opin Biotechnol 18 (2007) 295-304.

[21] E.R. Goldman, J.L. Liu, D. Zabetakis, G.P. Anderson, Enhancing Stability of Camelid and Shark Single Domain Antibodies: An Overview, Front. Immunol. 8 (2017) 865.

[22] C. Vincke, S. Muyldermans, Introduction to Heavy Chain Antibodies and Derived Nanobodies, in: D. Saerens, S. Muyldermans (Eds.) Single Domain Antibodies, Humana Press, Totowa, NJ, 2012 pp. 15-26.

[23] S. Muyldermans, Nanobodies, Annu. Rev. Biochem. 82 (2013) 775-797.

[24] J. Rios-Doria, J. Harper, R. Rothstein, L. Wetzel, J. Chesebrough, A. Marrero, C. Chen, P. Strout, K. Mulgrew, K. McGlinchey, R. Fleming, B. Bezabeh, J. Meekin, D. Stewart, M. Kennedy, P. Martin, A. Buchanan, N. Dimasi, E. Michelotti, R. Hollingsworth, Antibody-Drug Conjugates Bearing Pyrrolobenzodiazepine or Tubulysin Payloads Are Immunomodulatory and Synergize with Multiple Immunotherapies, Cancer Res 77 (2017) 2686-2698.

[25] A.C. Phillips, E.R. Boghaert, K.S. Vaidya, H.D. Falls, M.J. Mitten, P.J. DeVries, L. Benatuil, C.M. Hsieh, J.A. Meulbroek, S.C. Panchal, F.G. Buchanan, K.R. Durbin, M.J. Voorbach, D.R. Reuter, S.R. Mudd, L.I. Loberg, S.L. Ralston, D. Cao, H.K. Gan, A.M. Scott, E.B. Reilly, Characterization of ABBV-221, a Tumor-Selective EGFR-Targeting Antibody Drug Conjugate, Mol Cancer Ther 17 (2018) 795-805.

[26] D. Zhang, S.-F. Yu, S.C. Khojasteh, Y. Ma, T.H. Pillow, J.D. Sadowsky, D. Su, K.R. Kozak, K. $\mathrm{Xu}$, A.G. Polson, P.S. Dragovich, C.E.C.A. Hop, Intratumoral Payload Concentration Correlates with the Activity of Antibody-Drug Conjugates, Mol Cancer Ther 17 (2018) 677-685.

[27] T.M. Cardillo, S.V. Govindan, M.B. Zalath, D.L. Rossi, Y. Wang, C.-H. Chang, D.M. Goldenberg, IMMU-140, a Novel SN-38 Antibody-Drug Conjugate Targeting HLA-DR, Mediates Dual Cytotoxic Effects in Hematologic Cancers and Malignant Melanoma, Mol Cancer Ther 17 (2018) 150-160.

[28] S. Bhakta, L.M. Crocker, Y. Chen, M. Hazen, M.M. Schutten, D. Li, C. Kuijl, R. Ohri, F. Zhong, K.A. Poon, M.A.T. Go, E. Cheng, R. Piskol, R. Firestein, A. Fourie-O’Donohue, K.R. Kozak, H. Raab, J.-A. Hongo, D. Sampath, M.S. Dennis, R.H. Scheller, P. Polakis, J.R. Junutula, An Anti-GDNF 
Family Receptor Alpha 1 (GFRA1) Antibody-Drug Conjugate for the Treatment of Hormone

Receptor-Positive Breast Cancer, Mol Cancer Ther 17 (2018) 638-649.

[29] R. Klooster, B.T.H. Maassen, J.C. Stam, P.W. Hermans, M.R. ten Haaft, F.J.M. Detmers, H.J. de Haard, J.A. Post, C. Theo Verrips, Improved anti-IgG and HSA affinity ligands: clinical application of VHH antibody technology, J Immunol Methods 324 (2007) 1-12.

[30] M. Kijanka, F.-J. Warnders, M. El Khattabi, M. Lub-de Hooge, G.M. van Dam, V. Ntziachristos, L. de Vries, S. Oliveira, P.M.P. van Bergen en Henegouwen, Rapid optical imaging of human breast tumour xenografts using anti-HER2 VHHs site-directly conjugated to IRDye 800CW for imageguided surgery, Eur J Nucl Med Mol Imaging 40 (2013) 1718-1729.

[31] M.M. Kijanka, A.S.A. van Brussel, E. van der Wall, W.P.T.M. Mali, P.J. van Diest, P.M.P. van Bergen en Henegouwen, S. Oliveira, Optical imaging of pre-invasive breast cancer with a combination of VHHs targeting CAIX and HER2 increases contrast and facilitates tumour characterization, EJNMMI Res 6 (2016) 109.

[32] M. Kijanka, E.G. van Donselaar, W.H. Müller, B. Dorresteijn, D. Popov-Čeleketić, M. el Khattabi, C.T. Verrips, P.M.P. van Bergen en Henegouwen, J.A. Post, A novel immuno-gold labeling protocol for nanobody-based detection of HER2 in breast cancer cells using immuno-electron microscopy, Journal of Structural Biology 199 (2017) 1-11.

[33] M. Vandesquille, T. Li, C. Po, C. Ganneau, P. Lenormand, C. Dudeffant, C. Czech, F. Grueninger, C. Duyckaerts, B. Delatour, M. Dhenain, P. Lafaye, S. Bay, Chemically-defined camelid antibody bioconjugate for the magnetic resonance imaging of Alzheimer's disease, MAbs 9 (2017) 1016-1027.

[34] J.A. Boutin, A.L. Tartar, A. van Dorsselaer, H. Vaudry, General lack of structural characterization of chemically synthesized long peptides, Protein Sci 28 (2019) 857-867.

[35] I.A. Kaltashov, C.E. Bobst, R.R. Abzalimov, G. Wang, B. Baykal, S. Wang, Advances and challenges in analytical characterization of biotechnology products: mass spectrometry-based approaches to study properties and behavior of protein therapeutics, Biotechnol Adv 30 (2012) 210222.

[36] U. Leurs, U.H. Mistarz, K.D. Rand, Getting to the core of protein pharmaceuticalsComprehensive structure analysis by mass spectrometry, Eur J Pharm Biopharm 93 (2015) 95-109.

[37] M. Tassi, J. de Vos, S. Chatterjee, F. Sobott, J. Bones, S. Eeltink, Advances in native highperformance liquid chromatography and intact mass spectrometry for the characterization of biopharmaceutical products, J Sep Sci 41 (2018) 125-144.

[38] P. Bannas, J. Hambach, F. Koch-Nolte, Nanobodies and Nanobody-Based Human Heavy Chain Antibodies As Antitumor Therapeutics, Front. Immunol. 8 (2017) 1603.

[39] P. Bannas, F. Koch-Nolte, Perspectives for the Development of CD38-Specific Heavy Chain Antibodies as Therapeutics for Multiple Myeloma, Front. Immunol. 9 (2018) 2559.

[40] M.F. Bush, Z. Hall, K. Giles, J. Hoyes, C.V. Robinson, B.T. Ruotolo, Collision cross sections of proteins and their complexes: a calibration framework and database for gas-phase structural biology, Anal Chem 82 (2010) 9557-9565.

[41] V. Gabelica, A.A. Shvartsburg, C. Afonso, P. Barran, J.L.P. Benesch, C. Bleiholder, M.T. Bowers, A. Bilbao, M.F. Bush, J.L. Campbell, I.D.G. Campuzano, T. Causon, B.H. Clowers, C.S. Creaser, E. de Pauw, J. Far, F. Fernandez-Lima, J.C. Fjeldsted, K. Giles, M. Groessl, C.J. Hogan, S. Hann, H.I. Kim, R.T. Kurulugama, J.C. May, J.A. McLean, K. Pagel, K. Richardson, M.E. Ridgeway, 
F. Rosu, F. Sobott, K. Thalassinos, S.J. Valentine, T. Wyttenbach, Recommendations for reporting ion

mobility Mass Spectrometry measurements, Mass Spectrom Rev 38 (2019) 291-320.

[42] J.D. Eschweiler, J.N. Rabuck-Gibbons, Y. Tian, B.T. Ruotolo, CIUSuite, Anal. Chem. 87 (2015) $11516-11522$.

[43] J. Lobstein, C.A. Emrich, C. Jeans, M. Faulkner, P. Riggs, M. Berkmen, SHuffle, a novel Escherichia coli protein expression strain capable of correctly folding disulfide bonded proteins in its cytoplasm, Microb Cell Fact 11 (2012) 327.

[44] M. Maggi, C. Scotti, Enhanced expression and purification of camelid single domain VHH antibodies from classical inclusion bodies, Protein Expression and Purification 136 (2017) 39-44.

[45] V.K. Dagar, Adivitiya, Y.P. Khasa, High-level expression and efficient refolding of therapeutically important recombinant human Interleukin-3 (hIL-3) in E. coli, Protein Expression and Purification 131 (2017) 51-59.

[46] K. Tsumoto, M. Umetsu, I. Kumagai, D. Ejima, J.S. Philo, T. Arakawa, Role of arginine in protein refolding, solubilization, and purification, Biotechnol Prog 20 (2004) 1301-1308.

[47] R.C. Roovers, M.J.W.D. Vosjan, T. Laeremans, R. el Khoulati, R.C.G. de Bruin, K.M. Ferguson, A.J. Verkleij, G.A.M.S. van Dongen, P.M.P. van Bergen en Henegouwen, A biparatopic anti-EGFR nanobody efficiently inhibits solid tumour growth, Int J Cancer 129 (2011) 2013-2024.

[48] P. Manavalan, W.C. Johnson, Sensitivity of circular dichroism to protein tertiary structure class, Nature 305 (1983) 831-832.

[49] A. Micsonai, F. Wien, É. Bulyáki, J. Kun, É. Moussong, Y.-H. Lee, Y. Goto, M. Réfrégiers, J. Kardos, BeStSel, Nucleic Acids Res 46 (2018) W315-W322.

[50] A. Micsonai, F. Wien, L. Kernya, Y.-H. Lee, Y. Goto, M. Réfrégiers, J. Kardos, Accurate secondary structure prediction and fold recognition for circular dichroism spectroscopy, Proc Natl Acad Sci U S A 112 (2015) E3095-103.

[51] K.R. Schmitz, A. Bagchi, R.C. Roovers, P.M.P. van Bergen en Henegouwen, K.M. Ferguson, Structural Evaluation of EGFR Inhibition Mechanisms for Nanobodies/VHH Domains, Structure 21 (2013) 1214-1224.

[52] Z. Hall, C.V. Robinson, Do charge state signatures guarantee protein conformations?, J Am Soc Mass Spectrom 23 (2012) 1161-1168.

[53] I.A. Kaltashov, R.R. Abzalimov, Do ionic charges in ESI MS provide useful information on macromolecular structure?, J Am Soc Mass Spectrom 19 (2008) 1239-1246.

[54] K. Lorenzen, E. van Duijn, Native mass spectrometry as a tool in structural biology, Curr Protoc Protein Sci Chapter 17 (2010) Unit17.12.

[55] A. Natalello, C. Santambrogio, R. Grandori, Are Charge-State Distributions a Reliable Tool Describing Molecular Ensembles of Intrinsically Disordered Proteins by Native MS?, J Am Soc Mass Spectrom 28 (2017) 21-28.

[56] G.R. Masson, M.L. Jenkins, J.E. Burke, An overview of hydrogen deuterium exchange mass spectrometry (HDX-MS) in drug discovery, Expert Opin Drug Discov 12 (2017) 981-994.

[57] A.J. Percy, M. Rey, K.M. Burns, D.C. Schriemer, Probing protein interactions with hydrogen/deuterium exchange and mass spectrometry-a review, Anal Chim Acta 721 (2012) 7-21.

[58] M.J. Chalmers, S.A. Busby, B.D. Pascal, G.M. West, P.R. Griffin, Differential hydrogen/deuterium exchange mass spectrometry analysis of protein-ligand interactions, Expert Rev Proteomics 8 (2011) 43-59. 
[59] G. Terral, T. Champion, F. Debaene, O. Colas, M. Bourguet, E. Wagner-Rousset, N. Corvaia, A. Beck, S. Cianferani, Epitope characterization of anti-JAM-A antibodies using orthogonal mass

[60] N.M. Duc, Y. Du, C. Zhang, S.Y. Lee, T.S. Thorsen, B.K. Kobilka, K.Y. Chung, Effective application of bicelles for conformational analysis of $\mathrm{G}$ protein-coupled receptors by hydrogen/deuterium exchange mass spectrometry, J Am Soc Mass Spectrom 26 (2015) 808-817.

[61] D.P. O’Brien, B. Hernandez, D. Durand, V. Hourdel, A.-C. Sotomayor-Pérez, P. Vachette, M. Ghomi, J. Chamot-Rooke, D. Ladant, S. Brier, A. Chenal, Structural models of intrinsically disordered and calcium-bound folded states of a protein adapted for secretion, Scientific Reports 5 (2015) 14223.

[62] J. Lu, R.A. Harrison, L. Li, M. Zeng, S. Gondi, D. Scott, N.S. Gray, J.R. Engen, K.D. Westover, KRAS G12C Drug Development: Discrimination between Switch II Pocket Configurations Using Hydrogen/Deuterium-Exchange Mass Spectrometry, Structure 25 (2017) 1442-1448.e3.

[63] M.B. Trelle, D.M. Dupont, J.B. Madsen, P.A. Andreasen, T.J.D. Jørgensen, Dissecting the effect of RNA aptamer binding on the dynamics of plasminogen activator inhibitor 1 using hydrogen/deuterium exchange mass spectrometry, ACS Chem Biol 9 (2014) 174-182.

[64] V. Katta, B.T. Chait, Conformational changes in proteins probed by hydrogen-exchange electrospray-ionization mass spectrometry, Rapid Commun Mass Spectrom 5 (1991) 214-217.

[65] C.C. Going, Z. Xia, E.R. Williams, Real-time HD Exchange Kinetics of Proteins from Buffered Aqueous Solution with Electrothermal Supercharging and Top-Down Tandem Mass Spectrometry, J Am Soc Mass Spectrom 27 (2016) 1019-1027.

[66] H. Xiao, I.A. Kaltashov, Transient structural disorder as a facilitator of protein-ligand binding: native H/D exchange-mass spectrometry study of cellular retinoic acid binding protein I, J Am Soc Mass Spectrom 16 (2005) 869-879.

[67] F. Lanucara, S.W. Holman, C.J. Gray, C.E. Eyers, The power of ion mobility-mass spectrometry for structural characterization and the study of conformational dynamics, Nat Chem 6 (2014) 281-294.

[68] C. Uetrecht, R.J. Rose, E. van Duijn, K. Lorenzen, A.J.R. Heck, Ion mobility mass spectrometry of proteins and protein assemblies, Chem Soc Rev 39 (2010) 1633-1655.

[69] J. Seo, W. Hoffmann, S. Warnke, M.T. Bowers, K. Pagel, G. von Helden, Retention of Native Protein Structures in the Absence of Solvent: A Coupled Ion Mobility and Spectroscopic Study, Angew Chem Int Ed Engl 55 (2016) 14173-14176.

[70] C. Atmanene, D. Chaix, Y. Bessin, N. Declerck, A. van Dorsselaer, S. Sanglier-Cianferani, Combination of noncovalent mass spectrometry and traveling wave ion mobility spectrometry reveals sugar-induced conformational changes of central glycolytic genes repressor/DNA complex, Anal. Chem. 82 (2010) 3597-3605.

[71] C. Atmanene, S. Petiot-Bécard, D. Zeyer, A. van Dorsselaer, V. Vivat Hannah, S. SanglierCianférani, Exploring key parameters to detect subtle ligand-induced protein conformational changes using traveling wave ion mobility mass spectrometry, Anal Chem 84 (2012) 4703-4710.

[72] J. Stojko, S. Fieulaine, S. Petiot-Bécard, A. van Dorsselaer, T. Meinnel, C. Giglione, S. Cianférani, Ion mobility coupled to native mass spectrometry as a relevant tool to investigate extremely small ligand-induced conformational changes, Analyst 140 (2015) 7234-7245.

[73] S.M. Dixit, D.A. Polasky, B.T. Ruotolo, Collision induced unfolding of isolated proteins in the gas phase: past, present, and future, Curr Opin Chem Biol 42 (2018) 93-100. 
[74] J.N. Rabuck-Gibbons, J.E. Keating, B.T. Ruotolo, Collision induced unfolding and dissociation differentiates ATP-competitive from allosteric protein tyrosine kinase inhibitors, International Journal of Mass Spectrometry 427 (2018) 151-156.

[75] T. Botzanowski, S. Erb, O. Hernandez-Alba, A. Ehkirch, O. Colas, E. Wagner-Rousset, D. Rabuka, A. Beck, P.M. Drake, S. Cianférani, Insights from native mass spectrometry approaches for top- and middle- level characterization of site-specific antibody-drug conjugates, MAbs 9 (2017) 801811.

[76] O. Hernandez-Alba, E. Wagner-Rousset, A. Beck, S. Cianférani, Native Mass Spectrometry, Ion Mobility, and Collision-Induced Unfolding for Conformational Characterization of IgG4 Monoclonal Antibodies, Anal Chem 90 (2018) 8865-8872.

[77] F. van Bockstaele, J.-B. Holz, H. Revets, The development of nanobodies for therapeutic applications, Curr Opin Investig Drugs 10 (2009) 1212-1224.

[78] T. Abrams, A. Connor, C. Fanton, S.B. Cohen, T. Huber, K. Miller, E.E. Hong, X. Niu, J. Kline, M. Ison-Dugenny, S. Harris, D. Walker, K. Krauser, F. Galimi, Z. Wang, M. Ghoddusi, K. Mansfield, S.T. Lee-Hoeflich, J. Holash, N. Pryer, W. Kluwe, S.A. Ettenberg, W.R. Sellers, E. Lees, P. Kwon, J.A. Abraham, S.C. Schleyer, Preclinical Antitumor Activity of a Novel Anti-c-KIT Antibody-Drug Conjugate against Mutant and Wild-type c-KIT-Positive Solid Tumors, Clin Cancer Res 24 (2018) 4297-4308.

[79] L.J. Thomas, L. Vitale, T. O’Neill, R.Y. Dolnick, P.K. Wallace, H. Minderman, L.E. Gergel, E.M. Forsberg, J.M. Boyer, J.R. Storey, C.D. Pilsmaker, R.A. Hammond, J. Widger, K. Sundarapandiyan, A. Crocker, H.C. Marsh, T. Keler, Development of a Novel Antibody-Drug Conjugate for the Potential Treatment of Ovarian, Lung, and Renal Cell Carcinoma Expressing TIM-1, Mol Cancer Ther 15 (2016) 2946-2954.

[80] K. Almhanna, T. Kalebic, C. Cruz, J.E. Faris, D.P. Ryan, J. Jung, T. Wyant, A.A. Fasanmade, W. Messersmith, J. Rodon, Phase I Study of the Investigational Anti-Guanylyl Cyclase Antibody-Drug Conjugate TAK-264 (MLN0264) in Adult Patients with Advanced Gastrointestinal Malignancies, Clin Cancer Res 22 (2016) 5049-5057.

[81] M. Bacchi, B. Fould, M. Jullian, A. Kreiter, A. Maurras, O. Nosjean, T. Coursindel, K. Puget, G. Ferry, J.A. Boutin, Screening ubiquitin specific protease activities using chemically synthesized ubiquitin and ubiquitinated peptides, Anal Biochem 519 (2017) 57-70.

[82] M. Bacchi, M. Jullian, S. Sirigu, B. Fould, T. Huet, L. Bruyand, M. Antoine, L. Vuillard, L. Ronga, L.M.G. Chavas, O. Nosjean, G. Ferry, K. Puget, J.A. Boutin, Total chemical synthesis, refolding, and crystallographic structure of fully active immunophilin calstabin 2 (FKBP12.6), Protein Sci 25 (2016) 2225-2242.

[83] L. Hartmann, T. Botzanowski, M. Galibert, M. Jullian, E. Chabrol, G. Zeder-Lutz, V. Kugler, J. Stojko, J.-M. Strub, G. Ferry, L. Frankiewicz, K. Puget, R. Wagner, S. Cianférani, J.A. Boutin, VHH characterization. Comparison of recombinant with chemically synthesized anti-HER2 VHH, Protein Sci (2019).

[84] H. Nakayama, A. Murakami, M. Yoshida, J. Muraoka, J. Wakai, N. Kenjyou, Y. Ito, Characterization and Selection of 3-(1-Naphthoyl)-Indole Derivative-Specific Alpaca VHH Antibodies Using a Phage Display Library, Monoclon Antib Immunodiagn Immunother 35 (2016) 231-234. 
952 [85] J.L. Liu, L.C. Shriver-Lake, D. Zabetakis, G.P. Anderson, E.R. Goldman, Selection and 953 characterization of protective anti-chikungunya virus single domain antibodies, Mol Immunol 105 954 (2019) 190-197.

955 [86] G. Hussack, S. Raphael, M.J. Lowden, K.A. Henry, Isolation and characterization of camelid 956 single-domain antibodies against HER2, BMC Res Notes 11 (2018) 866.

957 [87] S. Wöll, C. Bachran, S. Schiller, M. Schröder, L. Conrad, R. Scherließ, L.K. Swee, Sortagging of 958 liposomes with a murine CD11b-specific VHH increases in vitro and in vivo targeting specificity of 959 myeloid cells, Eur J Pharm Biopharm 134 (2019) 190-198.

960 [88] F. Faraji, N. Tajik, M. Behdani, M.A. Shokrgozar, A.H. Zarnani, F. Shahhosseini, M. Habibi961 Anbouhi, Development and characterization of a camelid single-domain antibody directed to human 962 CD22 biomarker, Biotechnology and Applied Biochemistry 65 (2018) 718-725.

963 [89] L. Schoonaert, L. Rué, B. Roucourt, M. Timmers, S. Little, L. Chávez-Gutiérrez, M. Dewilde, P. 964 Joyce, A. Curnock, P. Weber, J. Haustraete, G. Hassanzadeh-Ghassabeh, B. de Strooper, L. van den 965 Bosch, P. van Damme, R. Lemmens, W. Robberecht, Identification and characterization of $966 \quad$ Nanobodies targeting the EphA4 receptor, J Biol Chem 292 (2017) 11452-11465.

967 
Table 1: VHH production and refolding yields from the different bacterial expression systems evaluated.

971

\begin{tabular}{llcc} 
Sample name & $\begin{array}{l}\text { Bacteria strain/ } \\
\text { Production localization }\end{array}$ & $\begin{array}{c}\text { Production Yield } \\
\mathbf{( m g / L ~ o f ~ c u l t u r e ~})\end{array}$ & $\begin{array}{c}\text { Refolding process yield } \\
\mathbf{( \% )}\end{array}$ \\
\hline Anti-HER2 PS & E.coli & $\approx 1$ & $\mathrm{ND}$ \\
& BL21(DE3)/Periplasmic & & $\mathrm{ND}$ \\
Anti-HER2 Cyto & E.coli BL21(DE3)/Cytosolic & $\approx 10$ & $\mathrm{ND}$ \\
Anti-HER2 Shu & E.coli Shuffle T7/Cytosolic & $\approx 10$ & $\approx 90$ \\
Anti-HER2 RO & E.coli BL21(DE3)/Cytosolic & $\approx 100$ & $\approx 75$ \\
Anti-HER2 RR & E.coli BL21(DE3)/Cytosolic & $\approx 100$ & $\mathrm{ND}$ \\
Anti-EGFR & E.coli Shuffle T7/Cytosolic & $\approx 10$ & $\mathrm{ND}$ \\
Anti-HSA & E.coli Shuffle T7/Cytosolic & $\approx 10$ &
\end{tabular}

974 Note: ND: not determined 


\begin{tabular}{lccc} 
Sample name & Injected mass $(\boldsymbol{\mu g})$ & Mass recovery $(\mathbf{\%})$ & Mw (Da) \\
\hline Anti-HER2 PS & 21.60 & 88.8 & $14500 \pm 195$ \\
Anti-HER2 Cyto & 18.80 & 103.9 & $14730 \pm 334$ \\
Anti-HER2 Shu & 21.60 & 95.6 & $14670 \pm 223$ \\
Anti-HER2 RO & 17.40 & 101.5 & $14930 \pm 397$ \\
Anti-HER2 RR & 21.60 & 80.1 & $14630 \pm 182$ \\
Anti-EGFR & 19.00 & 104.1 & $15450 \pm 329$ \\
Anti-HSA & 21.60 & 92.3 & $13730 \pm 547$ \\
\hline
\end{tabular}

978

979

980

981

982 
Table 3: Relative UV quantification and MS assignment of VHH species revealed by LC-UV-MS.

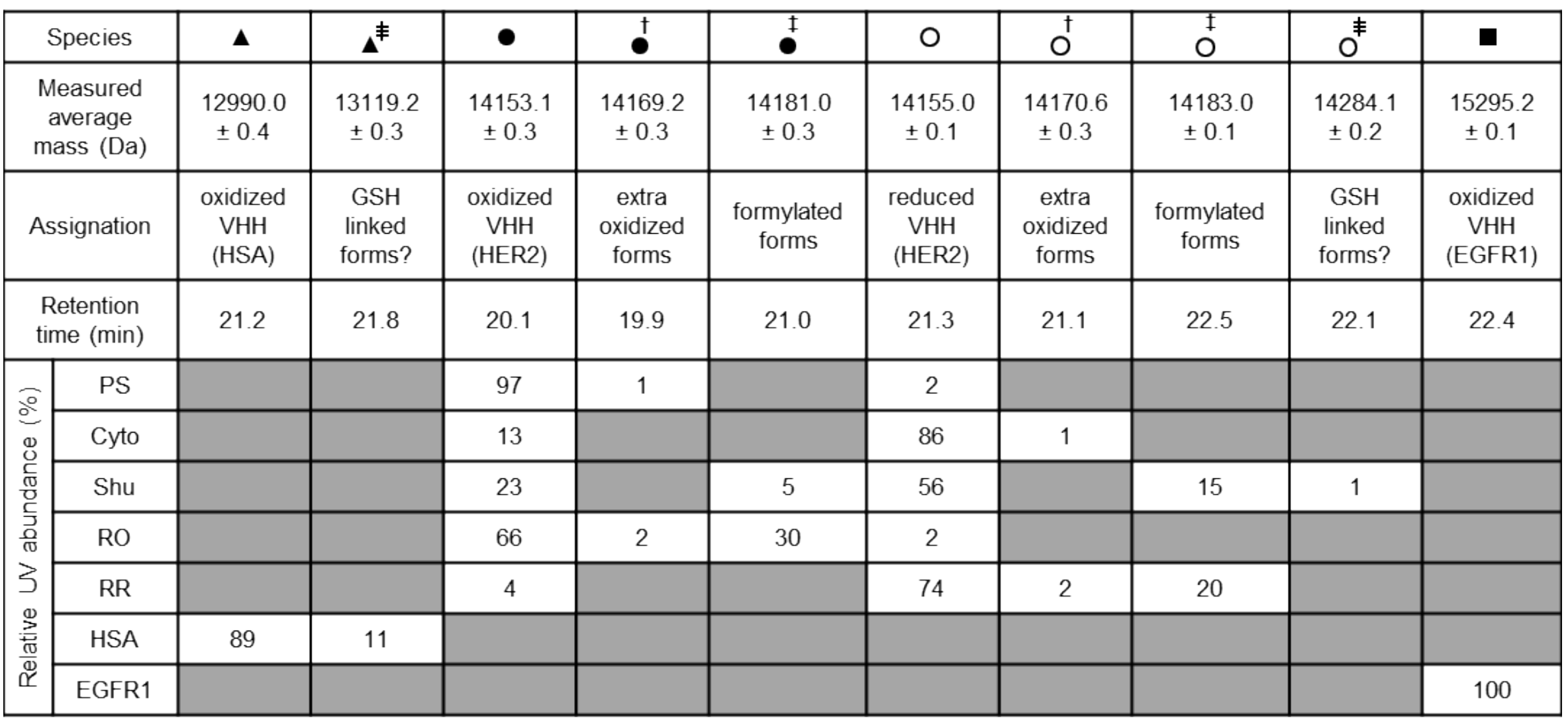


990

\begin{tabular}{llll} 
& $\begin{array}{l}\text { kon } \pm \mathbf{S D} \\
\left(\mathbf{M}^{-1} \mathbf{s}^{-1}\right) \mathbf{E}^{+\mathbf{6}}\end{array}$ & $\begin{array}{l}\text { koff } \pm \mathbf{S D} \\
\left(\mathbf{s}^{-1}\right) \mathbf{E}^{-\mathbf{3}}\end{array}$ & $\begin{array}{l}\text { Kd } \pm \mathbf{S D} \\
(\mathbf{n M})\end{array}$ \\
\hline Anti-HER2 PS & $5.39 \pm 0.13$ & $4.85 \pm 0.13$ & $0.9 \pm 0.00$ \\
Anti-HER2 Cyto & $4.54 \pm 0.05$ & $2.77 \pm 0.01$ & $0.6 \pm 0.00$ \\
Anti-HER2 Shu & $3.83 \pm 0.03$ & $4.01 \pm 0.00$ & $1.05 \pm 0.01$ \\
Anti-HER2 RO & $3.05 \pm 0.01$ & $4.29 \pm 0.12$ & $1.4 \pm 0.04$ \\
Anti-HER2 RR & $3.35 \pm 0.06$ & $2.5 \pm 0.03$ & $0.7 \pm 0.00$ \\
Anti-EGFR1 & $0.20 \pm 0.01$ & $0.98 \pm 0.00$ & $4.8 \pm 0.03$ \\
Anti-HSA & $0.81 \pm 0.03$ & $9.22 \pm 0.22$ & $11.3 \pm 0.2$ \\
\hline
\end{tabular}


Table 5: CD spectra-derived secondary structures of the studied VHHs.

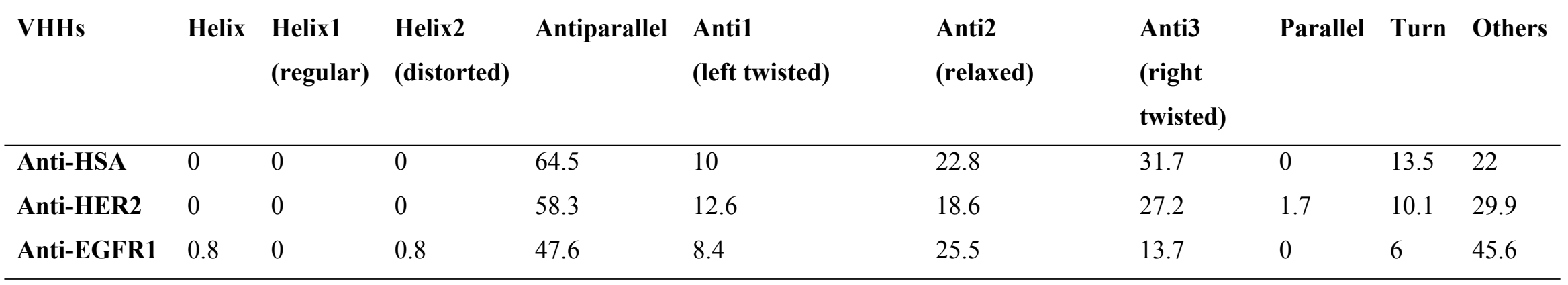

996 Note: Proportions of each secondary structure were determined from the CD spectra using the BeStSel online software. The values in brackets 997 correspond to the percentage of the anti1, anti2 and anti3 structure normalized to $100 \%$ of antiparallel structure. 
1001

1002

\section{Tm by CD}

$\left({ }^{\circ} \mathrm{C}\right)$

Tm1 by OPTIM with ratio $350 / 330 \mathrm{~nm}$

$\left({ }^{\circ} \mathrm{C}\right)$

$73.22 \pm 0.3$

$56.04 \pm 0.17$

$56.09 \pm 0.16$

$72.15 \pm 0.2$

$54.06 \pm 0.23$

$67.63 \pm 0.32$

$59.01 \pm 0.43$
Tm2 by OPTIM with ratio

$350 / 330 \mathrm{~nm}\left({ }^{\circ} \mathrm{C}\right)$

\begin{tabular}{lc}
\hline Anti-HER2 PS & $70.10 \pm 0.21$ \\
Anti-HER2 Cyto & $55.09 \pm 0.42$ \\
Anti-HER2 Shu & $54.93 \pm 0.58$ \\
Anti-HER2 RO & $70.04 \pm 0.18$ \\
Anti-HER2 RR & $\mathrm{ND}$ \\
Anti-EGFR1 & $65.50 \pm 0.46$ \\
Anti-HSA & $54.63 \pm 0.3$
\end{tabular}

1003

Note: * No second Tm was observed. ND: not determined 
Table 7: Deuterium uptake of oxidized and reduced anti-HER2 VHHs monitored by native HDX-MS.

\begin{tabular}{|c|c|c|c|c|c|}
\hline \multirow{2}{*}{\multicolumn{2}{|c|}{$\frac{\text { Samples }}{\text { Native species }}$}} & \multicolumn{2}{|c|}{$\mathrm{RO}$} & \multicolumn{2}{|c|}{ Cyto } \\
\hline & & ○ & ○ & $\mathrm{O}$ & 0 \\
\hline \multicolumn{2}{|c|}{ Assignation } & $\begin{array}{l}\text { Undeuterated } \\
\text { oxidized VHH }\end{array}$ & $\begin{array}{c}\text { Deuterated } \\
\text { oxidized VHH }\end{array}$ & $\begin{array}{l}\text { Undeuterated } \\
\text { reduced } \mathrm{VHH}\end{array}$ & $\begin{array}{c}\text { Deuterated } \\
\text { reduced VHH }\end{array}$ \\
\hline \multirow{3}{*}{ 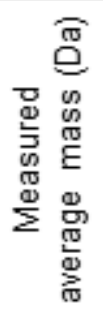 } & $\begin{array}{c}t_{0} \\
\text { (unlabeled) }\end{array}$ & $14153.8 \pm 0.3$ & & $14155.4 \pm 0.1$ & \\
\hline & $\begin{array}{c}t_{1 \min } \\
\left(\mathrm{D}_{2} \mathrm{O} \text { label }\right)\end{array}$ & & $14301.8 \pm 2.1$ & & $14304.6 \pm 1.0$ \\
\hline & $\begin{array}{c}\mathrm{t}_{1 \mathrm{hr}} \\
\left(\mathrm{D}_{2} \mathrm{O} \text { label }\right)\end{array}$ & & $14302.9 \pm 1.2$ & & $14305.0 \pm 1.3$ \\
\hline
\end{tabular}

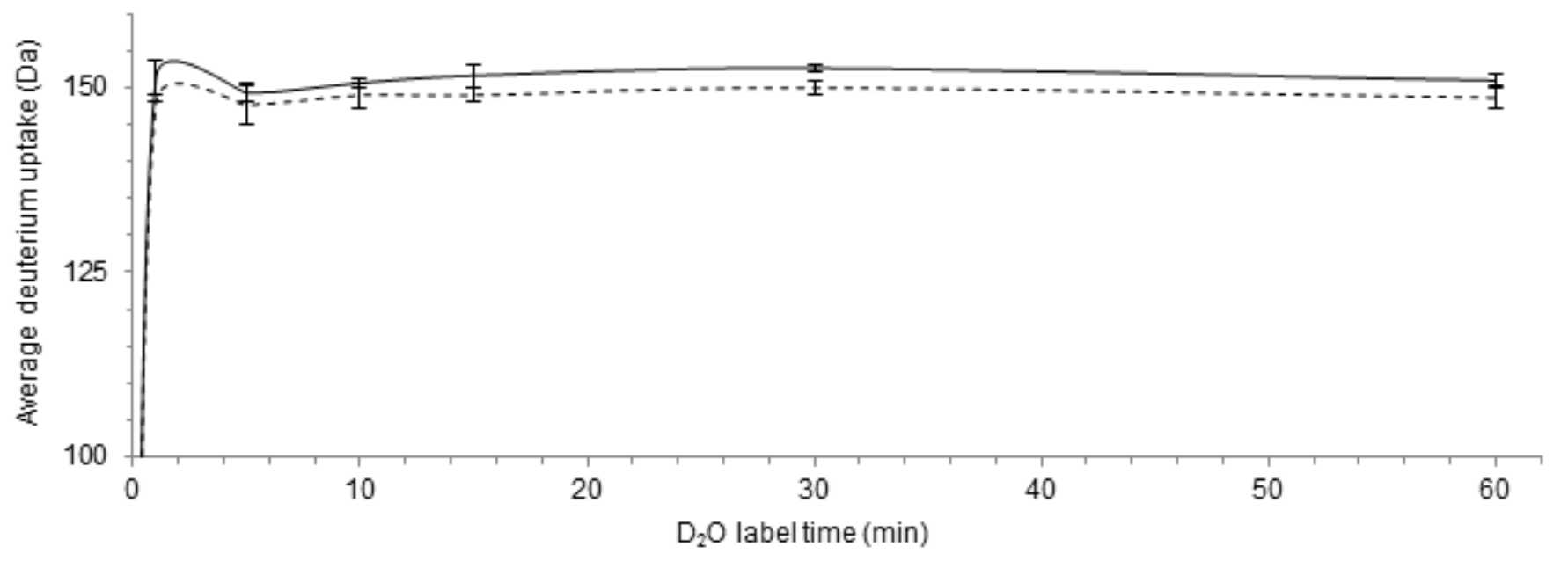

Average deuterium uptakes of oxidized (RO sample) and reduced (Cyto sample) native forms of anti-HER2 VHHs are plotted over label time as dashed and solid curves, respectively. Standard deviations displayed represent the experimental variability from sample triplicates for each label 1009 time. 
1012 Table 8: Conformational characterization of oxidized and reduced $\mathbf{8}^{+}$ions under native and activated states by IM-MS.

1013

1014

\begin{tabular}{|c|c|c|c|c|}
\hline $8^{+}$charge state & \multicolumn{2}{|c|}{ Reduced VHH } & \multicolumn{2}{|c|}{ Oxidized VHH } \\
\hline Conformer & O & 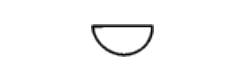 & & $v$ \\
\hline$t_{D}(m s)$ & $5.69 \pm 0.06$ & $7.06 \pm 0.00$ & $5.62 \pm 0.00$ & $6.61 \pm 0.00$ \\
\hline${ }^{\mathrm{TW}} \mathrm{CCS}_{\mathrm{N} 2 \rightarrow \mathrm{He}}\left(\mathrm{nm}^{2}\right)$ & $14.62 \pm 0.09$ & $15.69 \pm 0.02$ & $14.56 \pm 0.04$ & $15.36 \pm 0.02$ \\
\hline$\Delta^{\mathrm{TW}} \mathrm{CCS}_{\mathrm{N} 2 \rightarrow \mathrm{He}}(\%)$ & ref. & +7.3 & ref. & +5.5 \\
\hline
\end{tabular}

1015

1016

1017 Note: ${ }^{\mathrm{TW}} \mathrm{CCS}_{\mathrm{N} 2 \rightarrow \mathrm{He}}$ values of native reduced and oxidized conformations (open and filled circles, respectively) serve here as references (ref.) to 1018 express corresponding ${ }^{\mathrm{TW}} \mathrm{CCS}_{\mathrm{N} 2 \rightarrow \mathrm{He}}$ increases (\%) upon gas-phase activation. 
Legends to the figures:

1021 Figure 1: Sequence alignment of anti-HSA, anti-HER2 and anti-EGFR1 VHHs.

\section{Figure 2: SDS-Page 4-12\% in MES buffer of anti-HER2 VHH samples (A), anti-EGFR1 VHH} sample (B) and anti-HSA VHH sample (C) in non-reducing (NR) and reducing (R) conditions. NR

1024 conditions result in the addition of idoacetamine in the LDS buffer (Invitrogen) while the sample was 1025 boiled 2 minutes at $55^{\circ} \mathrm{C}$. R conditions correspond to the addition of $50 \mathrm{mM}$ DTT in the LDS buffer while 1026 the sample was boiled 5 minutes at $95^{\circ} \mathrm{C}$.

Figure 3: SEC-MALS chromatograms of the anti-HER2 VHH samples (A, B, C, D and E), antiEGFR1 and anti-HSA VHH (F, G) samples. Chromatograms of the different anti-HER2 VHH samples are showed in the panel A, B, C, D and E for the PS, Cyto, Shu, RO and RR samples respectively. The panel F shows the alignment of all anti-HER2 VHH sample chromatograms with in black line the PS, in 1031 dot line the Cyto, in blue line the Shu, in red line the RO and in green line the RR sample. In the panel G, 1032 the anti-EGFR1 chromatogram is represented in black line and the anti-HSA chromatogram in dot line. 1033 The $\mathrm{X}$ axis represents the elution time and the $\mathrm{Y}$ axis is expressed in a relative scale of the UV signal at $1034280 \mathrm{~nm}$.

Figure 4: VHHs redox state and microheterogeneity assessed by LC-UV-MS. RPLC-UV

1036 chromatograms at 280nm of denatured anti-HER2 VHH samples (A-F), anti-HSA (G) and anti-EGFR1 1037 VHH samples (H). A: PS; B: Cyto; C and F: Shu; D: RO; E: RR. Filled and open symbols respectively 1038 indicate oxidized (SS) and reduced (SH) forms of anti-HER2 (circle), anti-HSA (triangle) and anti-EGFR1 1039 (square) VHHs. Simple, double and triple crosses correspond to extra-oxidized, formylated and GSH1040 linked forms, respectively.

1041 Figure 5: SPR sensorgrams of anti-HER2, anti-EGFR1 and anti-HSA VHH samples. Anti-HER2 1042 VHH sensorgrams of the PS, Cyto, Shu, RO and RR samples are showed in the panel A, B, C, D and E, 
respectively. Anti-EGFR1 and anti-HSA VHH sensorgrams are represented in the panel F and G,

1044 respectively. Each curve corresponds to the kinetic of one concentration from $0.122 \mathrm{nM}$ to $62.5 \mathrm{nM}$ for the 1045 PS, Cyto, RO and RR samples; from $0.17 \mathrm{nM}$ to $40 \mathrm{nM}$ for the Shu sample; from $0.195 \mathrm{nM}$ to $100 \mathrm{nM}$ for 1046 the anti-EGFR1 VHH sample and from $0.39 \mathrm{nM}$ to $200 \mathrm{nM}$ for the anti-HSA VHH sample. The PS, Cyto, 1047 RO and RR samples were injected during 4 min while the Shu, anti-EGFR1 and anti-HSA VHH samples 1048 were injected during $6 \mathrm{~min}$. The dissociation time was 15 minutes for all samples excepted for the anti1049 EGFR1 where the dissociation time was done during 30 minutes. Experiments were performed in three 1050 concentration series starting from the lowest to the highest concentration but two series are showed in the 1051 figure. The $\mathrm{X}$ axis represents the time and the $\mathrm{Y}$ axis the response in RU.

1052 Figure 6: Circular dichroism spectra of the VHHs. Effect of the temperature. A: PS sample in black, 1053 Cyto in red, Shu in green and RO in blue. B: anti-EGFR1 and anti-HSA VHH samples are represented in 1054 black line and in dot line, respectively. CD spectra as a function of the temperature are showed in the 1055 panel C, D, E, F, G and H for the PS, Cyto, Shu, RO, anti-EGFR1 and anti-HSA VHH samples, 1056 respectively. Each spectrum corresponds to one temperature from $25^{\circ} \mathrm{C}$ to $85^{\circ} \mathrm{C}$. The panel I represents 1057 the CD value in mdeg at $217 \mathrm{~nm}$ for the anti-HER2 (PS in black, Cyto in red, Shu in green and RO in 1058 blue) and anti-EGFR1 VHHs (in orange) and at $220 \mathrm{~nm}$ for the anti-HSA VHH (in cyan). From these 1059 curves, the Tm of each sample was calculated using the following equation with Prism software:

$1060 \mathrm{Y}=\mathrm{Bottom}+($ Top-Bottom $) /\left(1+10^{\wedge}(\mathrm{X}-\mathrm{Tm})\right)$.

Figure 7: Intrinsic fluorescence of the VHHs as a function of the temperature. DSF experiments of

1062 anti-HER2 VHH samples are showed in the panel A, B, C, D and E for the PS, Cyto, Shu, RO and RR 1063 samples, respectively. DSF experiments of anti-EGFR1 and anti-HSA VHHs are represented in the panel $1064 \mathrm{~F}$ and $\mathrm{G}$, respectively. The $\mathrm{X}$-axis represents the temperature and the $\mathrm{Y}$-axis the fluorescence ratio at 350 1065 and $330 \mathrm{~nm}$. Each experiment was performed in triplicate and the bars represent the error of the 1066 measurement for each point. 

native MS. Denaturing (A) and native ESI-MS spectra (B) obtained from SS (top panel, PS sample) and

1070 SH-enriched forms (bottom panel, Cyto sample) of anti-HER2 VHH under infusion. Filled and open

1071 circles respectively mark oxidized (SS) and reduced (SH) charge state distributions of anti-HER2 VHH.

1072 Insets provide a zoom on a common charge state observed in denaturing $\left(11^{+}\right)$and native $\left(7^{+}\right)$conditions.

$1073 *$ indicate non-covalent acetate adducts $(+62 \mathrm{Da})$.

1074 Figure 9: Impact of the disulfide bridge on the anti-HER2 VHH SASA probed by native HDX-MS.

1075 Native ESI-MS spectra obtained from oxidized (A-C, RO sample) and reduced (D-F, Cyto sample) anti-

1076 HER2 VHHs in absence of $\mathrm{D}_{2} \mathrm{O}(\mathrm{A}, \mathrm{D})$ and after a $\mathrm{D}_{2} \mathrm{O}$ incubation of 1 minute $(\mathrm{B}, \mathrm{E})$ and 1 hour $(\mathrm{C}, \mathrm{F})$.

1077 Filled and open circles respectively indicate oxidized (SS) and reduced (SH) forms of anti-HER2 VHH.

1078 Black and orange coloured circles mark undeuterated and deuterated species. Double crosses correspond

1079 to extra-formylated forms. Insets provide a zoom on the common native charge state $7^{+}$observed in

1080 undeuterated and deuterated conditions.

1081 Figure 10: Impact of the disulfide bridge on the anti-HER2 VHH conformational stability probed

1082 by native IM-MS and collision-induced unfolding. A: Arrival time distributions of oxidized (dashed

1083 curves and filled symbols, PS sample) and reduced (solid curves and open symbols, Cyto sample) $8^{+}$

1084 charge states extracted from native IM-MS analyses upon various Trap collisional energies: 5V (top

1085 panel), $15 \mathrm{~V}$ (middle panel) and 60V (bottom panel). Symbols shape conceptualizes changes occurring in

1086 oxidized and reduced $8^{+}$ions conformation along gas-phase activation. B, C: Comparison of CIU

1087 fingerprints obtained between $8^{+}$native charge states from B Cyto (left, mostly reduced) and PS (right,

1088 mostly oxidized) samples, C RR (left, mostly reduced) and RO (right, mostly oxidized) samples. d) CIU

1089 fingerprint obtained from $8^{+}$native charge state of Shu sample (mixture of reduced and oxidized forms).

1090 


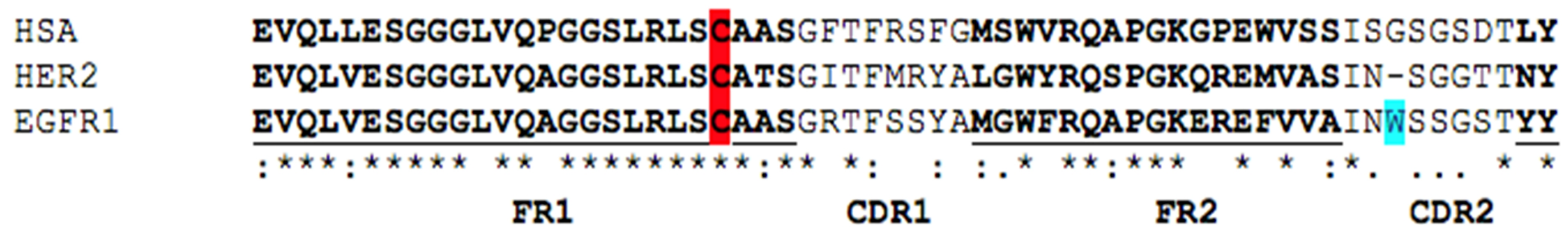

HSA ADSVKGRFTISRDNSK-TLYLQMNSLRPEDTAVYYCTIGGSLSRS------------SQG HER2 ADSVKGRFTISRDNAKNTVYLQMNSLKPEDTAVYYCNARWVKP------QFIDNNYWGQG EGFR1 ADSVKGRETISRDNAKNTMYLQMNSLKPEDTAVYYCAAGYQINSGNYNFKDYEYDYWGQG

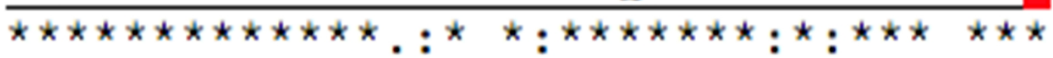
FR3

CDR3

$\begin{array}{ll}\text { HSA } & \text { TLVTVSS--- } \\ \text { HER2 } & \text { TQVTVSS--- } \\ \text { EGFR1 } & \frac{\text { TQVTVSSALE }}{\star \star \star \star \star \star \star}\end{array}$

FR4 


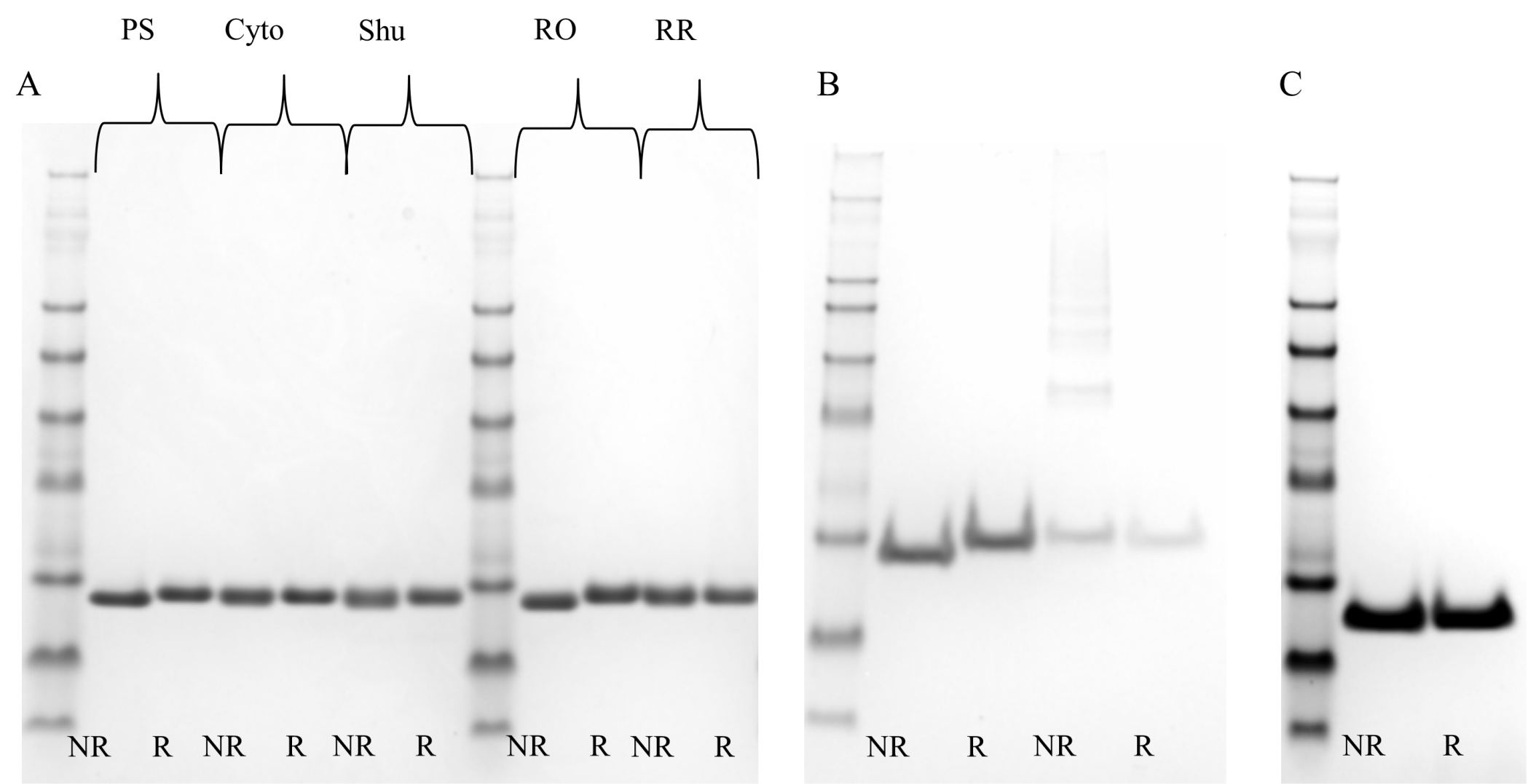

Figure 2 
A

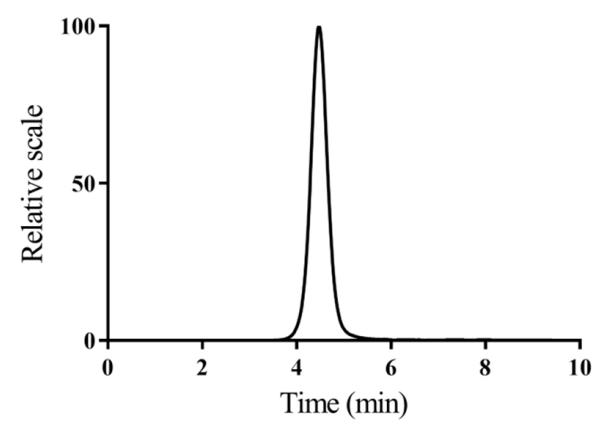

C

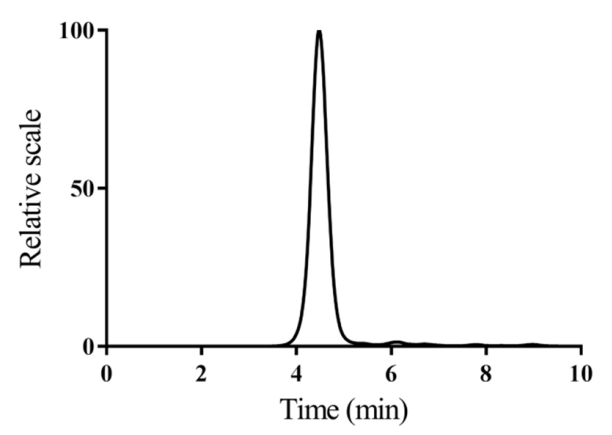

E

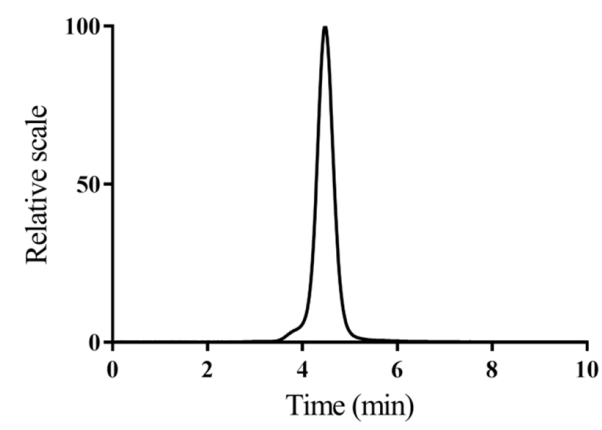

G

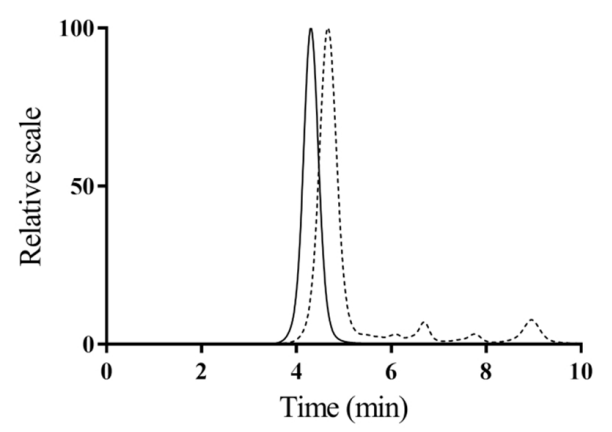

B

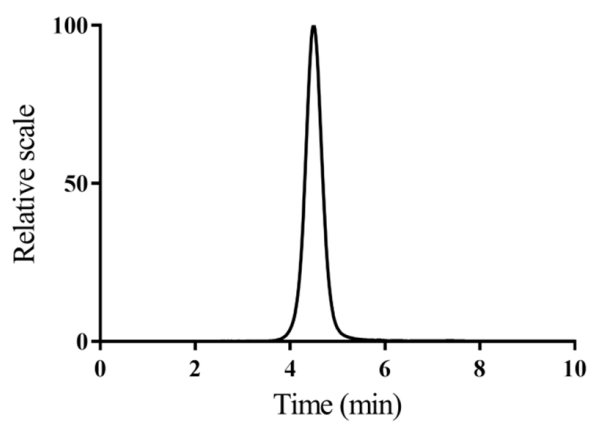

D

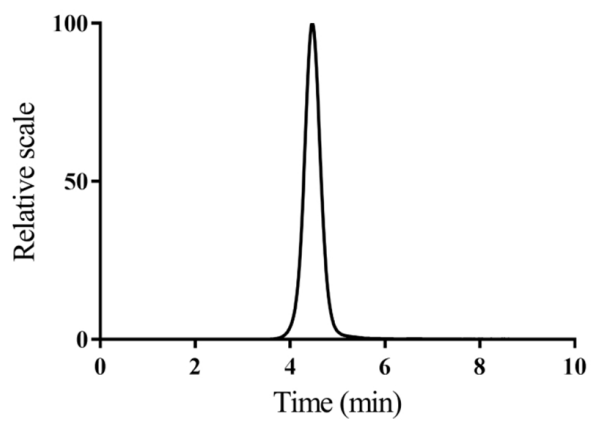

F

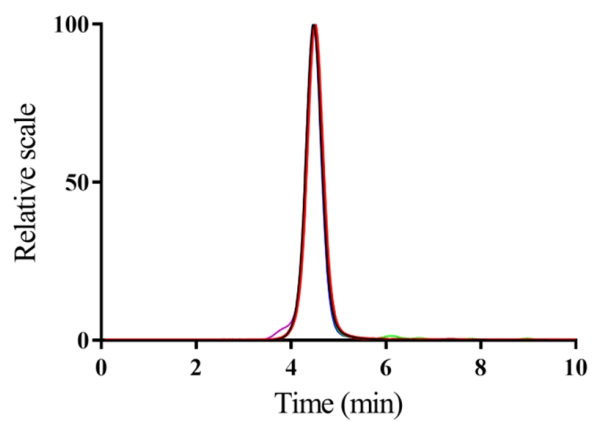

Figure 3 


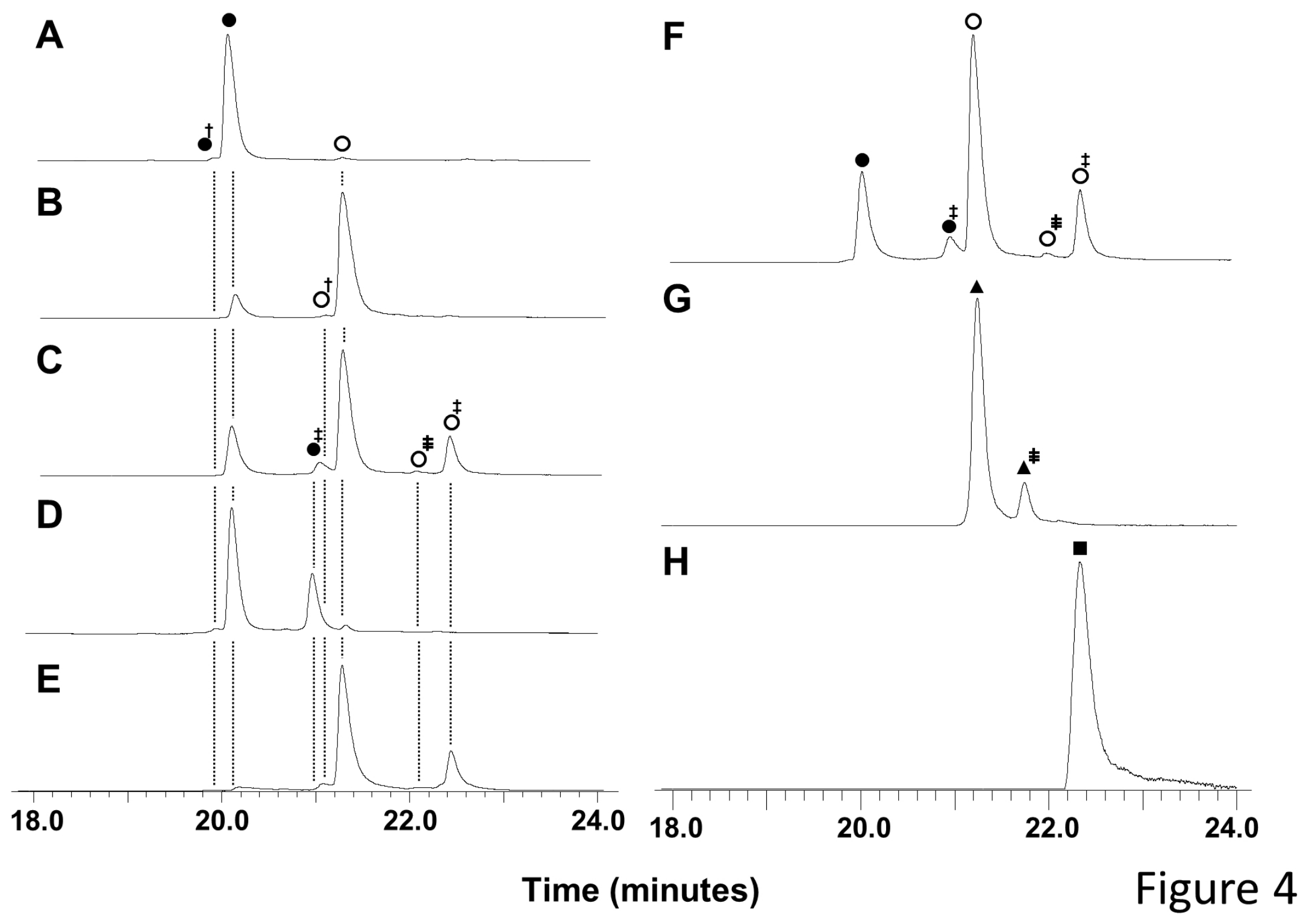


A

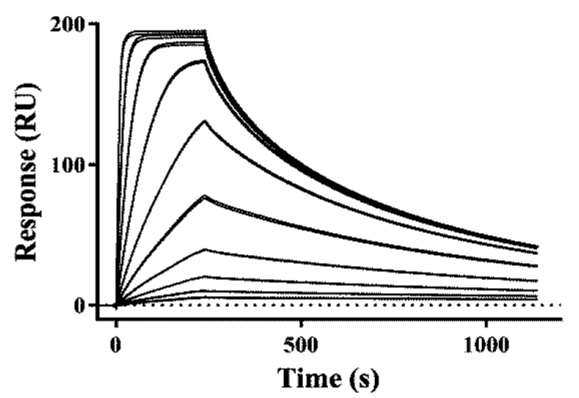

C

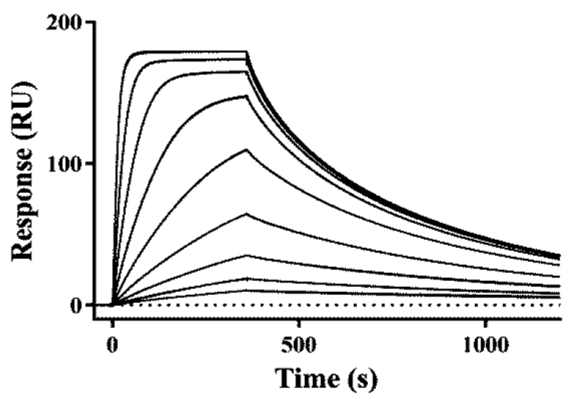

E

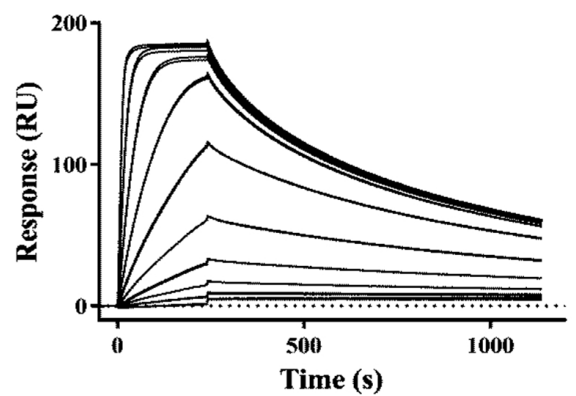

G

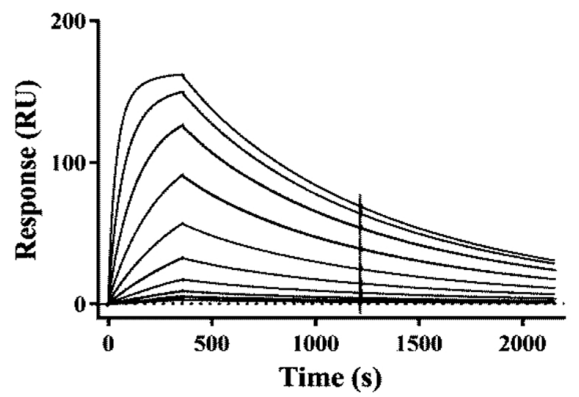

B

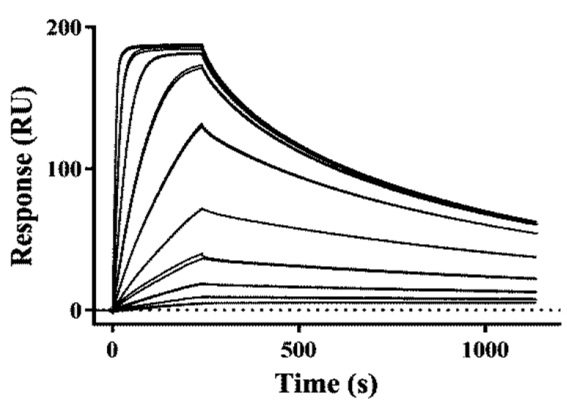

D

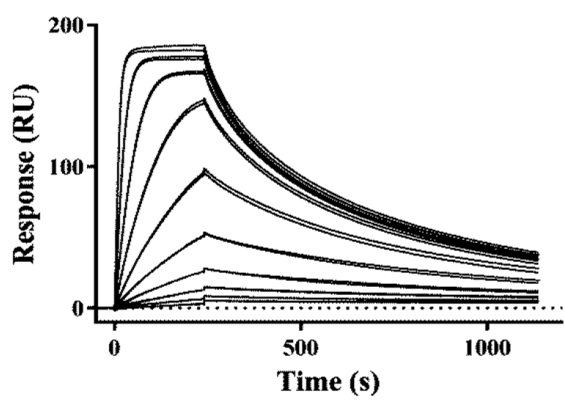

F
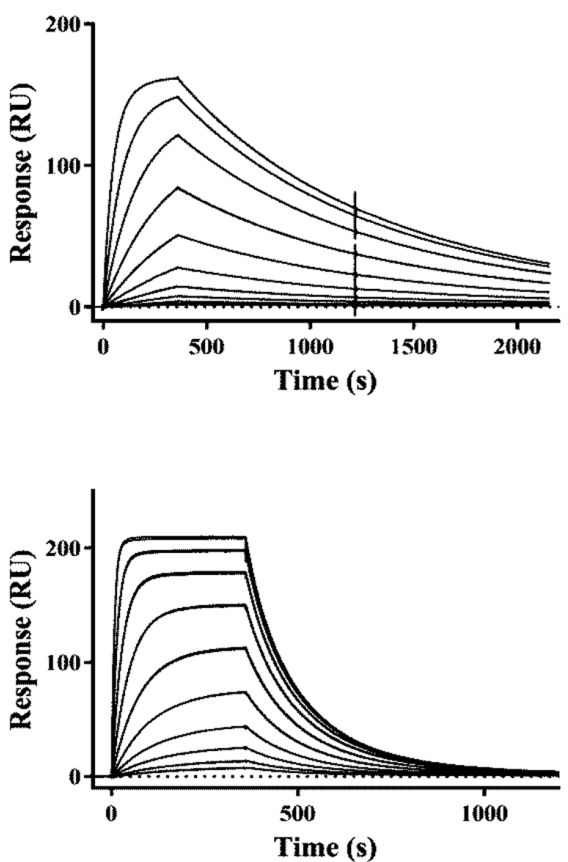

Figure 5 
A

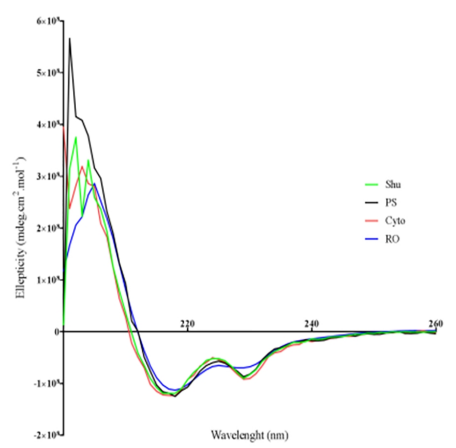

D

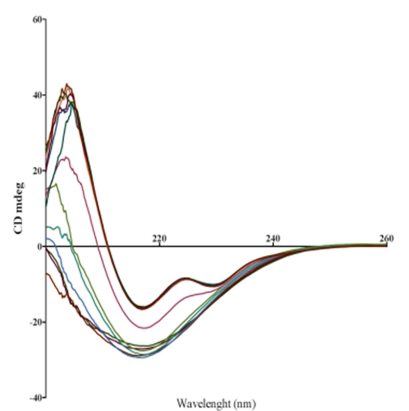

G

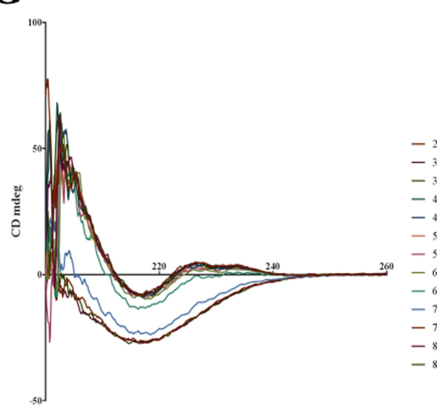

B

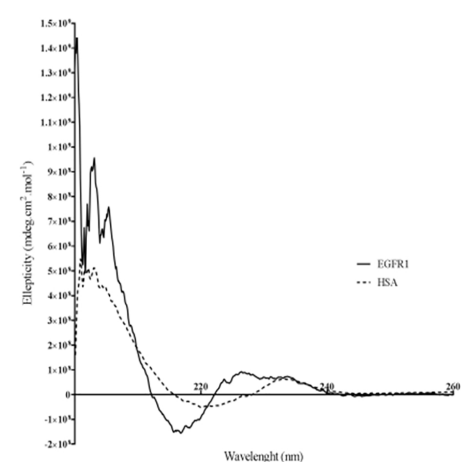

E

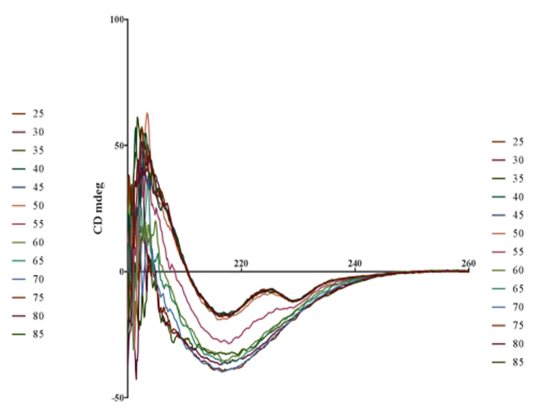

Wavelonght(nm)

H

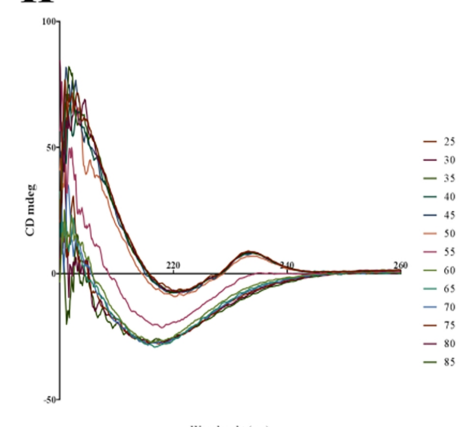

C

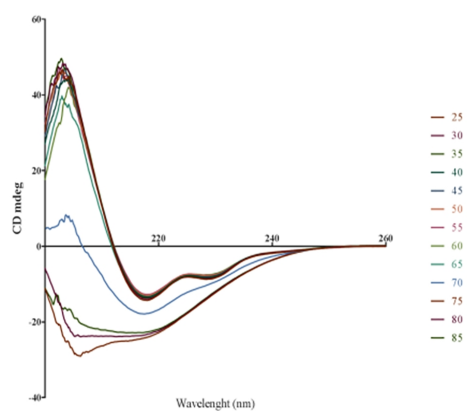

F

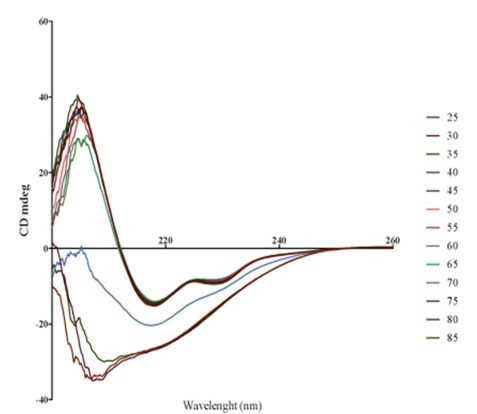

I

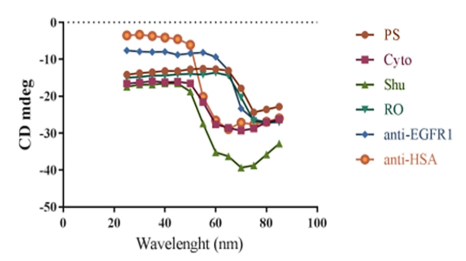

Figure 6 


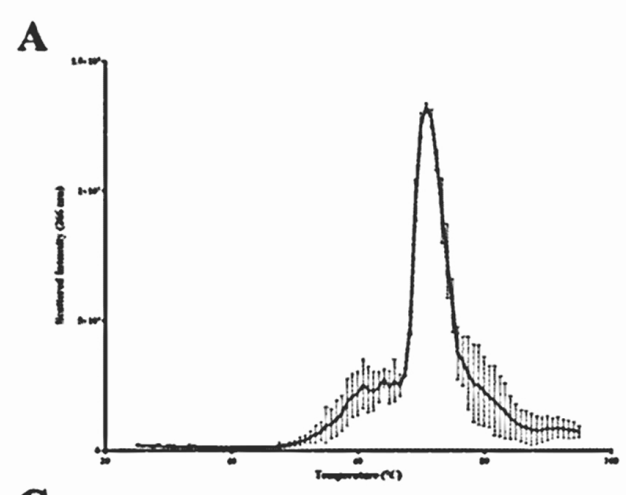

C

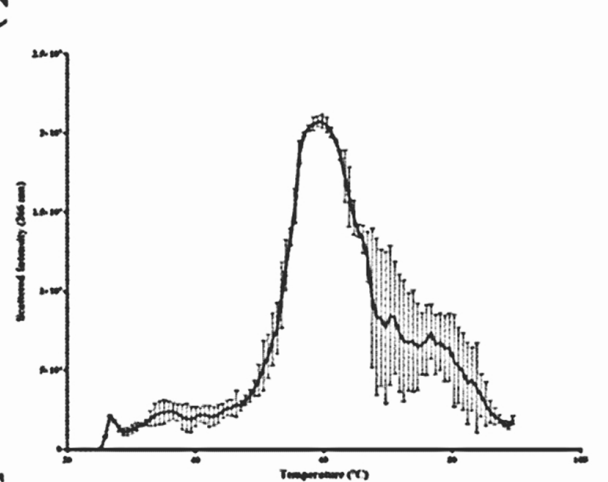

E

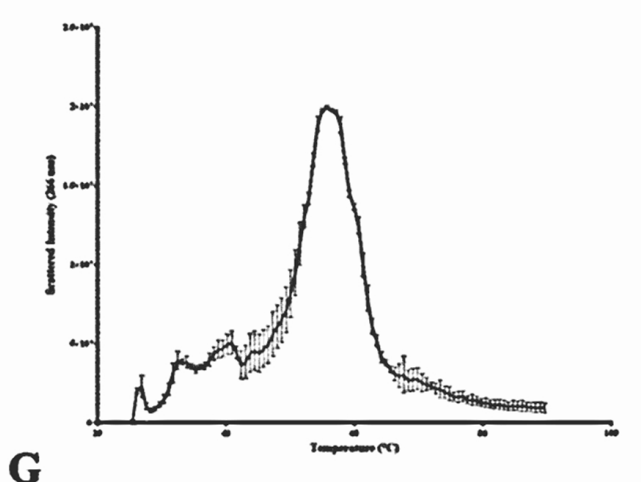

G

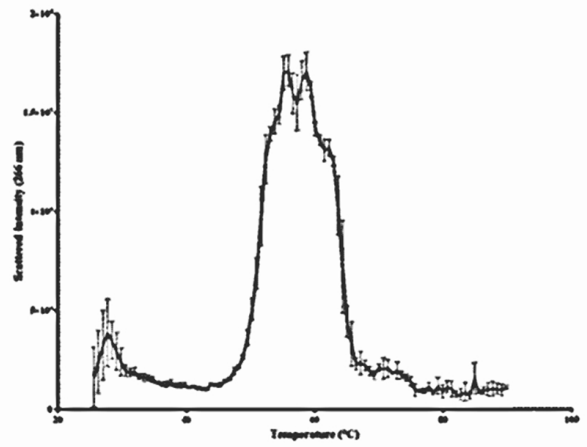

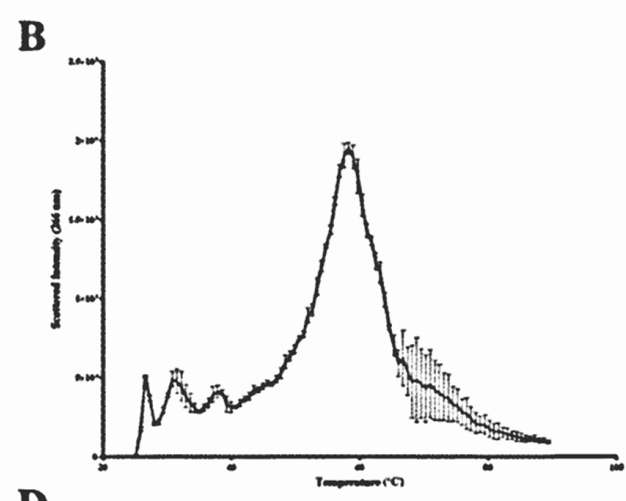

D

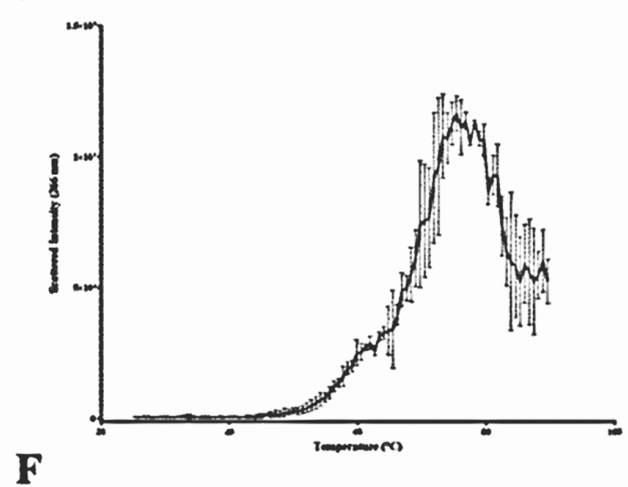

F

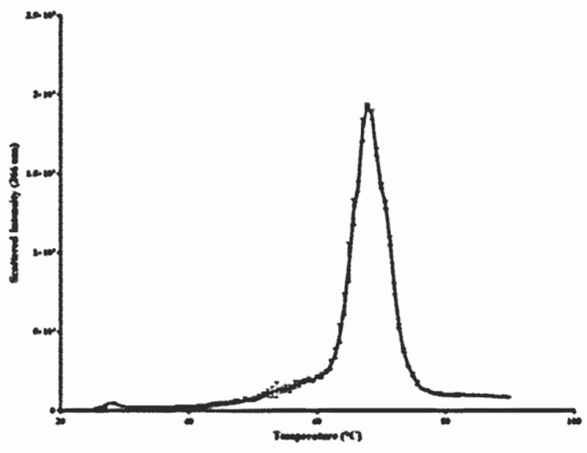

Figure 7 

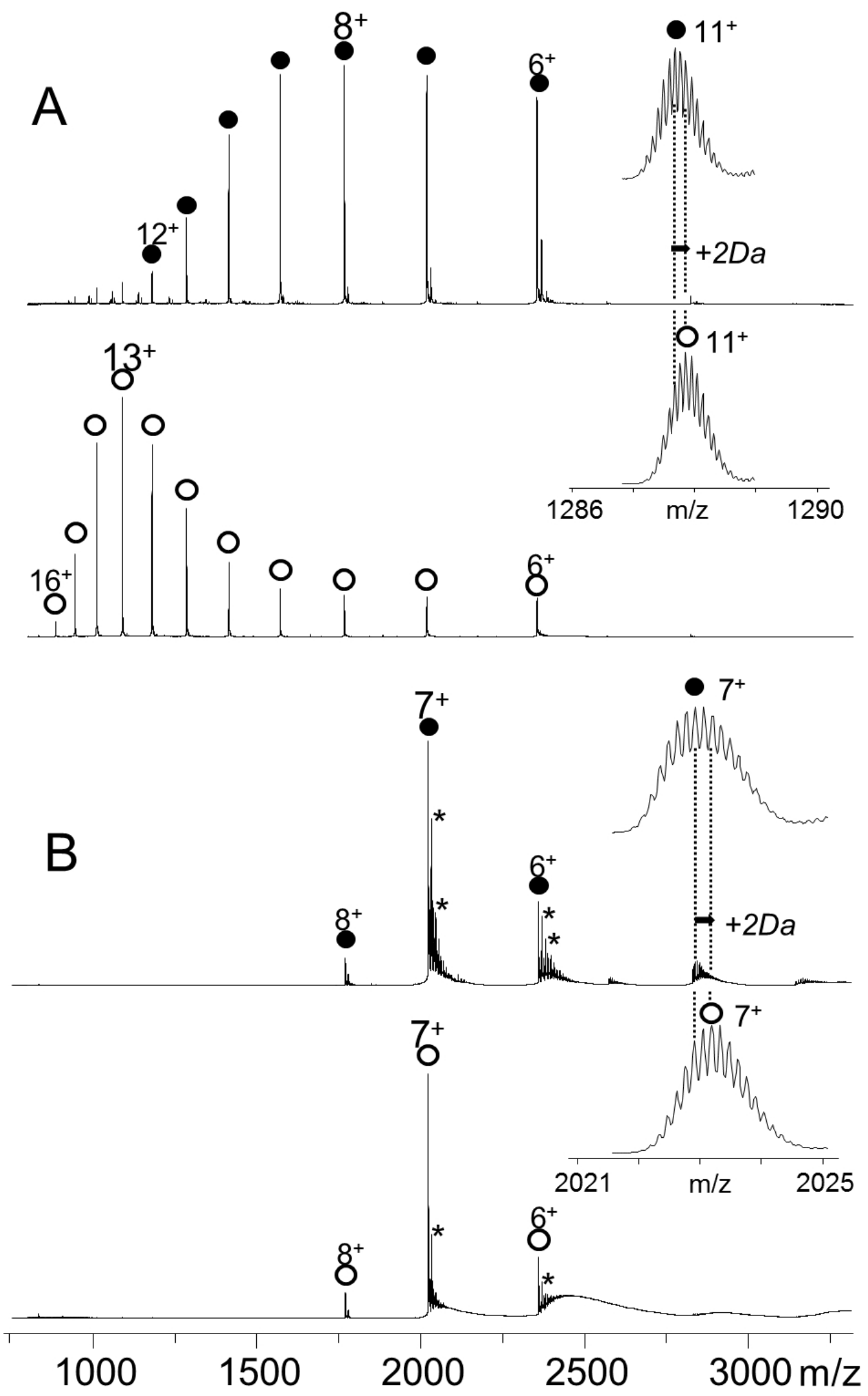

Figure 8 


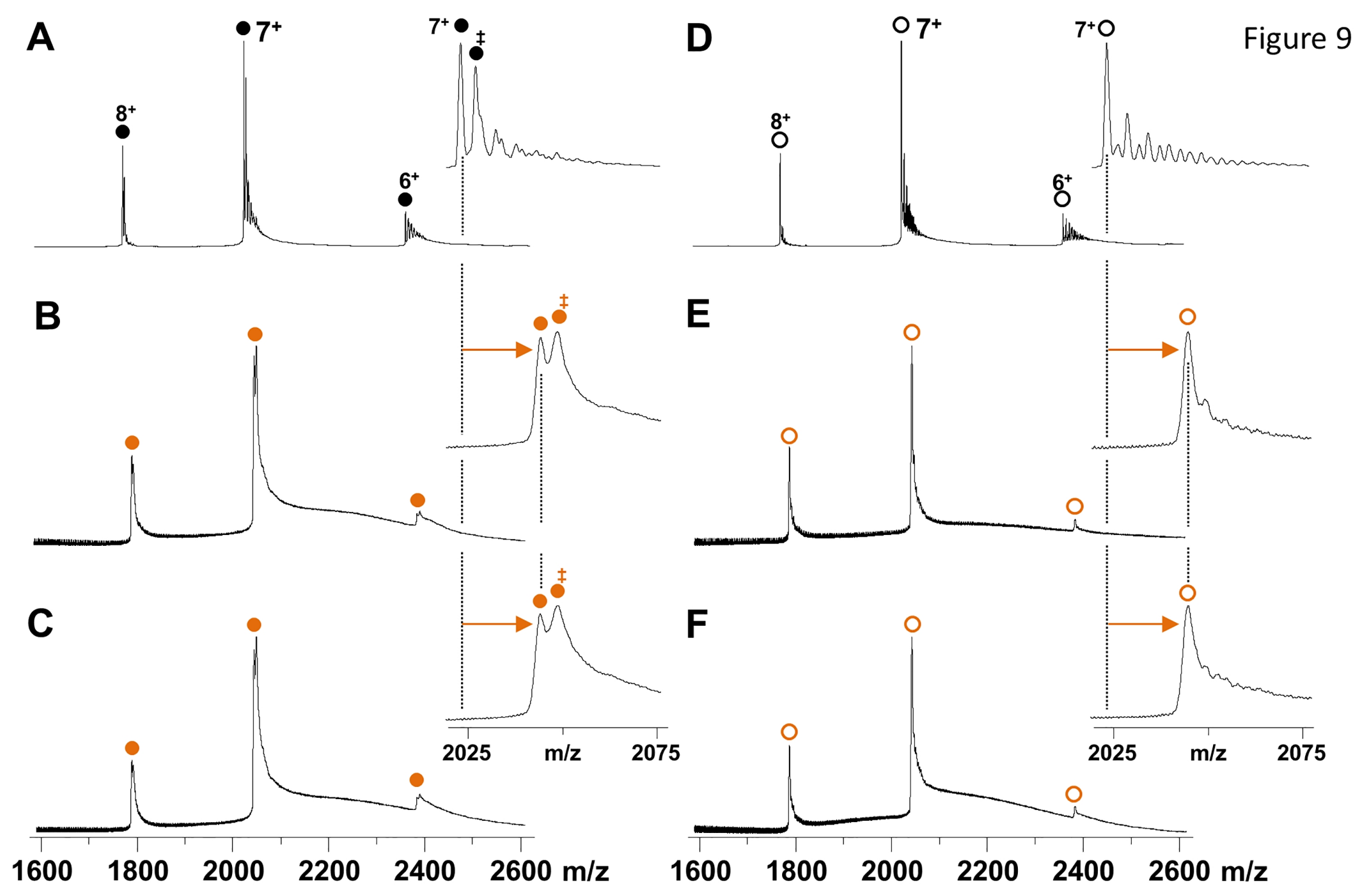



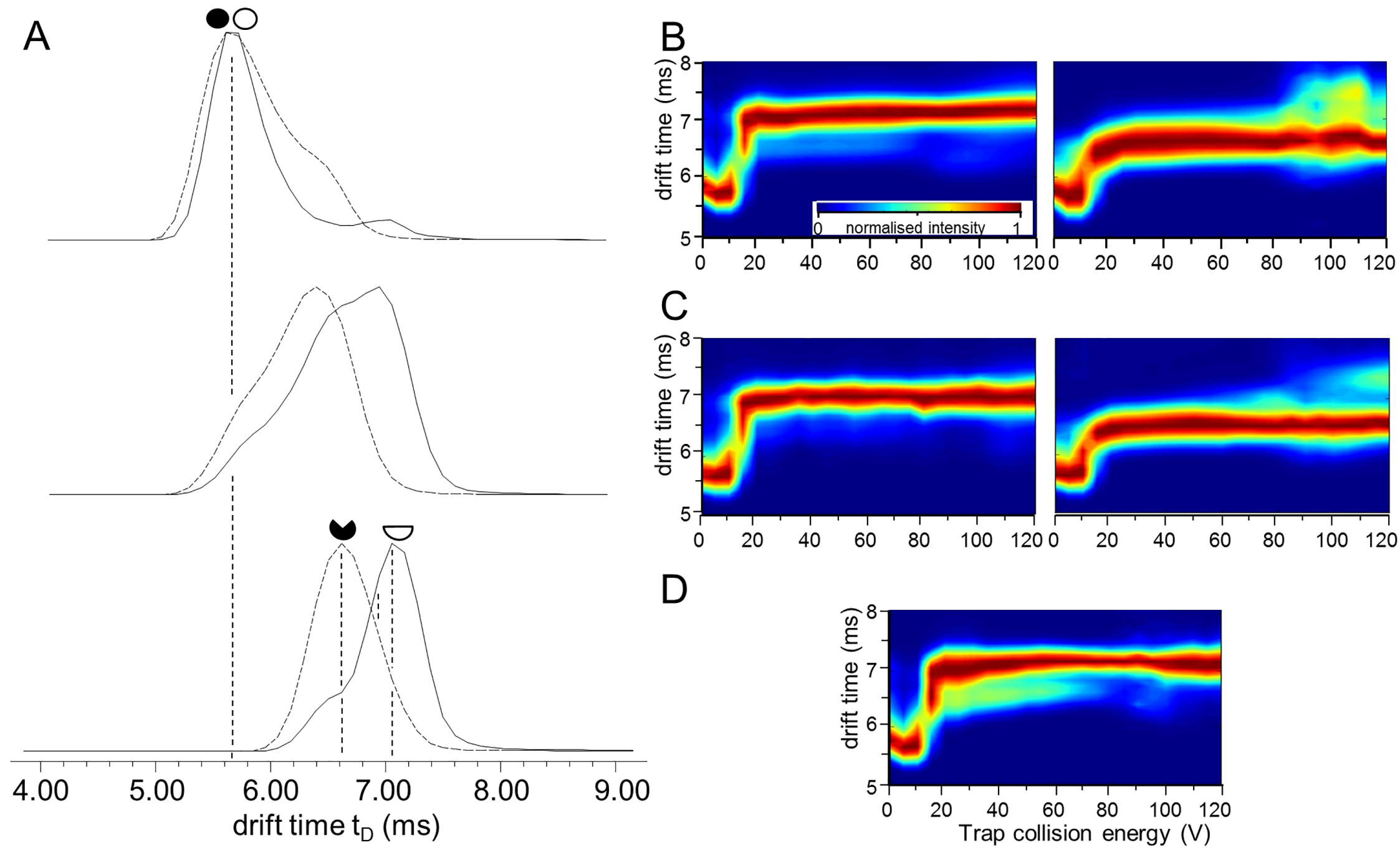

D

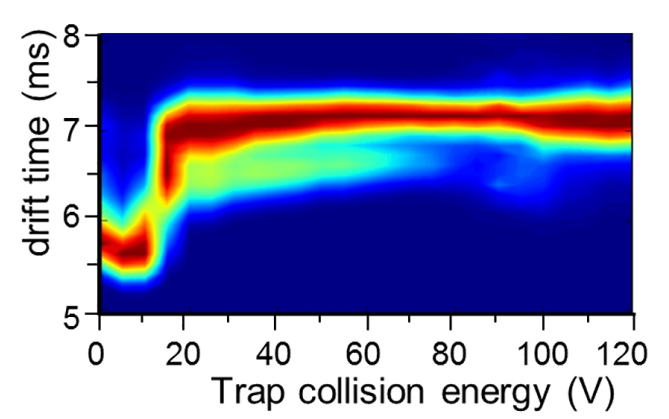

Figure 10 